\title{
CONSERVAÇÃO DA BIODIVERSIDADE: LEVANTAMENTO DA FAUNA EM UMA ÁREA DE CERRADO NO MUNICÍPIO DE JOÃO PINHEIRO-MG, COMO FERRAMENTA DE ENSINO PARA EDUCAÇÃO AMBIENTAL
}

\section{BIODIVERSITY CONSERVATION: SURVEY OF FAUNA IN A CERRADO AREA IN THE MUNICIPALITY OF JOÃO PINHEIRO-MG, AS A TEACHING TOOL FOR ENVIRONMENTAL EDUCATION}

\section{Cássia Crisélem Lobo Moura ${ }^{1}$, Keroly Cristine Soares de Oliveira² ${ }^{2}$ Wanderson Alves Pereira ${ }^{3}$, Saulo} Gonçalves Pereira ${ }^{4}$

Submetido em: 25/04/2021

Aprovado em: 15/05/2021

e24275

\section{RESUMO}

O levantamento de fauna é a utilização de técnicas para a análise das espécies de animais que compõem a biodiversidade de uma determinada área em certo período; e atua como mecanismo direto e com subsídios para sua conservação. Tais levantamentos são de grande importância para programas de conservação de fauna, e para processos de educação ambiental (EA). Para tanto, objetivou-se realizar um levantamento da fauna através de métodos primários e secundários em uma área de Vereda no município de João Pinheiro (MG), nas coordenadas (17 45'23.89"S $46^{\circ} 13^{\prime} 14.10^{\prime \prime}$ ), e ainda apresentar os dados verificando sua importância para o Tema Transversal "Educação Ambiental"; e, verificando como tal assunto está apresentado na Base Nacional Comum Curricular (BNCC). A metodologia utilizada foi o levantamento de fauna através do método de Avaliação Ecológica Rápida (AER), com as câmeras (armadilhas fotográficas Bushnell ( ), visualização direta, indireta e informações. Foram escolhidos 03 pontos onde foram instaladas as câmeras entre os dias 14/08 à 11/09/2020, ficando as mesmas expostas por 26 dias. Registraram-se 10 espécies na área durante o tempo de pesquisa; destas, 04 (quatro) encontramse em vulneráveis a extinção (VU) de acordo com o Livro Vermelho das espécies ameaçadas de extinção e o International Union for Conservation of Nature's (IUCN). Percebe-se que o levantamento de fauna a nível regional é de grande importância para processos de Educação Ambiental, bem como para conservação da fauna. O tema encontra-se inserido dentro dos temas transversais e dentro da BNCC na área temática meio ambiente, porém apenas como poucas orientações dentro das habilidades e competências.

PALAVRAS-CHAVE: Biodiversidade. Fauna. Meio Ambiente. Educação Ambiental.

\begin{abstract}
The survey of fauna is the use of techniques for the analysis of the species of animals that make up the biodiversity of a given area in a certain period of time; and acts as a direct mechanism with subsidies for its conservation. Such surveys are of great importance for wildlife conservation programs, and for environmental education (EA) processes. To this end, the objective was to conduct a survey of the fauna through primary and secondary methods in an area of Vereda in the

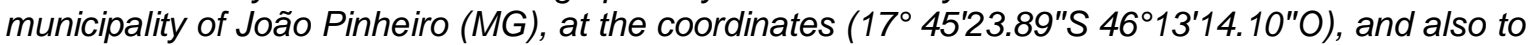
present the data verifying its importance for the Transversal Theme "Environmental Education"; and, verifying how such a subject is presented in the National Common Curriculum Base (BNCC). The methodology used was the survey of fauna through the Rapid Ecological Assessment (ERA) method, with cameras (Bushnell $\AA$ cameras), direct, indirect visualization and information. 03 points were chosen where the cameras were installed between 14/08 and 11/09/2020, being the
\end{abstract}

\footnotetext{
${ }^{1}$ Faculdade Cidade de João Pinheiro - MG

2 Faculdade Cidade de João Pinheiro - MG

${ }^{3}$ Faculdade Cidade de João Pinheiro - MG

${ }^{4}$ Graduado em Ciências Biológicas e Pedagogia, Doutor em Saúde Animal FPM e FCJP.
} 


\section{RECIMA21 - REVISTA CIENTÍFICA MULTIDISCIPLINAR ISSN 2675-6218}

CONSERVAÇÃO DA BIODIVERSIDADE: LEVANTAMENTO DA FAUNA EM UMA ÁREA DE CERRADO NO MUNICÍPIO DE JOÃO PINHEIRO-MG, COMO FERRAMENTA DE ENSINO PARA EDUCAÇÃO AMBIENTAL Cássia Crisélem Lobo Moura, Keroly Cristine Soares de Oliveira, Wanderson Alves Pereira, Saulo Gonçalves Pereira

same exposed for 07 days. 10 species were recorded in the area during the research time; of these, 04 (four) are vulnerable to extinction (VU) according to the Red Book of endangered species and the International Union for Conservation of Nature's (IUCN). Percebe-se que o levantamento de fauna a nível regional é de grande importância para processos de Educação Ambiental, bem como para conservação da fauna. The theme is inserted within the transversal themes and within the BNCC in the environmental thematic area, but only as few orientations within the skills and competencies.

KEYWORDS: Biodiversity. Fauna. Environment. Environmental education

\section{INTRODUÇÃO}

O cerrado brasileiro é o segundo bioma com maior extensão territorial, embora suas riquezas não sejam totalmente catalogadas, o que o deixa na contramão, pois é altamente ameaçado. As pesquisas sobre a fauna do cerrado são consideradas escassas. Assim, sua diversidade biológica é pouco conhecida. Há uma enorme necessidade de fazer estudos referentes à sua biodiversidade o quanto antes, pois a situação do bioma é crítica (DURIGAN et al. 2011).

A fauna é de extrema importância para a humanidade, em todos os aspectos, sejam eles culturais, ecológicos, científicos e econômicos. Infelizmente uma grande parcela da sociedade não entende essa importância, seja por falta de informação ou porque não tiveram acesso a uma Educação Ambiental, sabendo-se que as pessoas conservam aquilo que conhece (EA). (ANSELMO et al., 2013).

Segundo Klink e Machado (2005) e Oliveira e Pereira (2018), com o aumento das alterações ambientais provocadas indiretamente e diretamente pelo homem e devido algumas atividades que colocam em risco algumas espécies de animais e seu habitat, isso se deve principalmente à abertura de vias de acesso que facilitam práticas desregradas de atividades como a pecuária, a agricultura, a construção de hidrelétricas e a retirada ilegal de madeira da floresta, obrigando animais a migrarem e até mesmo morrerem nestes processos.

É importante a prática de conservação do cerrado, podendo influenciar na sobrevivência de muitas espécies, por isso a excelência da Educação Ambiental (EA) e seu costume, que busca desenvolver cidadãos conscientes, com conhecimento, atitudes, motivações, envoltura e habilidade, buscando resolver e prevenir problemas ambientais (ALVES, 2018).

A Educação Ambiental atua ajudando as pessoas a entenderem que cada um é parte do meio ambiente e propõe a reflexão sobre a construção dos caminhos que envolvem os aspectos dessa nova relação entre a humanidade e a natureza. Entende-se, portanto, que a "Educação Ambiental é condição necessária para modificar um quadro de crescente desolação socioambiental, embora ela por si só não seja suficiente" (PEREIRA, et al., 2017, p. 02).

O levantamento de fauna é a utilização de técnicas para fazer uma análise das espécies que tem como habitat uma determinada área, em certo período, atua como mecanismo direto e com subsídios para conservação da fauna e biodiversidade, bem como práticas de Educação Ambiental $(\mathrm{EA})$. 


\section{RECIMA21 - REVISTA CIENTÍFICA MULTIDISCIPLINAR ISSN 2675-6218}

CONSERVAÇÃO DA BIODIVERSIDADE: LEVANTAMENTO DA FAUNA EM UMA ÁREA DE CERRADO NO MUNICÍPIO DE JOÃO PINHEIRO-MG, COMO FERRAMENTA DE ENSINO PARA EDUCAÇÃO AMBIENTAL Cássia Crisélem Lobo Moura, Keroly Cristine Soares de Oliveira, Wanderson Alves Pereira, Saulo Gonçalves Pereira

O Município de João Pinheiro, que pertence ao estado de Minas Gerais, encontra-se em uma área de cerrado que é denominada Planalto Central, na qual podemos notar um relevo suavizado resultante de vários ciclos erosionais, contando com cerrado sentido restrito, pastagens, agricultura de sequeiro e irrigada, campo cerrado, matas e áreas de reflorestamento. As áreas que eram planas ou onduladas ganharam forma de pastagens e áreas de Reflorestamento (Eucalipto). Já as matas, denominadas ciliares, e as "veredas", estão presentes nas margens de córregos e nascentes onde há uma boa preservação (SAADI et al., 2005).

Acredita-se que a partir do reconhecimento da fauna de um local possa-se traçar mecanismos de Educação Ambiental (EA). Acredita-se, por fim, que através dos resultados de levantamento direto de fauna seja mais efetivo o trabalho de educação ambiental através da sensibilização para a sua conservação.

Além de sua biodiversidade, a fauna do cerrado vem sofrendo, ao longo dos anos, diversas pressões antrópicas, tais como queimadas, desmatamentos e restrições de habitat. Sendo assim, fazer o levantamento de fauna em âmbito regional torna-se um procedimento valioso, pois os resultados podem colaborar para processos educativos e para processos conservacionistas.

Estudos transversais para a região, tais como os de Educação Ambiental são levados em consideração para agregarem conhecimentos pertinentes a trabalhos futuros. Uma responsabilidade ambiental na qual a população poderá ter com esse estudo é um registro em forma de um banco de dados da fauna encontrada no local para conservação do meio ambiente.

Fazer o levantamento de fauna no município de João Pinheiro é de grande importância, pois assim será possível, através dos resultados encontrados, disponibilizá-los e, a partir de sua divulgação, acrescer o acervo de informação sobre a fauna com o intuito de conscientizar a comunidade escolar local sobre o quão é importante a conservação da fauna.

Nesse sentido, a Educação Ambiental contribuirá de forma transversal para a conscientização, pois cada dia que passa o meio ambiente vem se degradando, e isso acarretará danos para a fauna levando algumas espécies à extinção na região do município. Projetos como os de Educação Ambiental podem ser levados em consideração para agregarem conhecimentos pertinentes a trabalhos futuros de educação ambiental sobre a fauna da região.

Então, dessa maneira, objetivou-se desenvolver um levantamento de fauna de um fragmento de cerrado localizado no município de João Pinheiro, a fim de verificar a composição faunística e apresentar os dados verificando sua importância para o Tema Transversal "Educação Ambiental". Especificamente: desenvolver um levantamento bibliográfico com relação à biodiversidade de fauna no cerrado, construindo um levantamento de fauna quantitativo utilizando diversos métodos de observação para o levantamento de fauna na região, assim descrevendo como processos educativos podem conservar a fauna do cerrado, apontando uma correlação dentro da educação ambiental, os princípios conservativos, por fim formulando uma cartilha educativa e conscientizadora para a população local. (Cartilha em Anexo). 


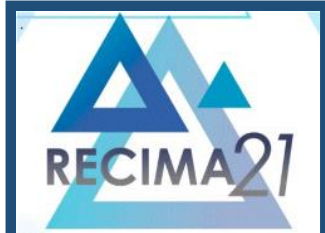

MATERIAL E MÉTODOS ÁREA DO ESTUDO

Este estudo foi procedido de acordo com os pressupostos de pesquisas qualitativas e quantitativas conforme apresta Gil (1999), e dividiu-se em duas etapas. Inicialmente foi realizado um levantamento exploratório de materiais publicados em sites especializados, revistas científicas e bases de dados, onde foram considerados artigos científicos, teses, dissertações e livros publicados preferencialmente entre 2005 a 2020. Tais informações foram compiladas e a partir delas foi realizada a revisão da literatura de forma narrativa.

Secundariamente foram realizados levantamentos de campo. A fazenda onde foi realizado o levantamento de campo está localizada na zona rural do município de João Pinheiro - MG, no noroeste do Estado. Nas coordenadas $17^{\circ} 45^{\prime} 23.89^{\prime \prime} S 46^{\circ} 13^{\prime} 14.10^{\prime \prime} \mathrm{O}$, conforme observado na figura 01, a seguir. O estudo foi realizado na área conhecida como "Vereda", cuja região é caracterizada como de Cerrado especificamente campos e Cerradão.

Figura 1 - Mapa de João Pinheiro e local do estudo.

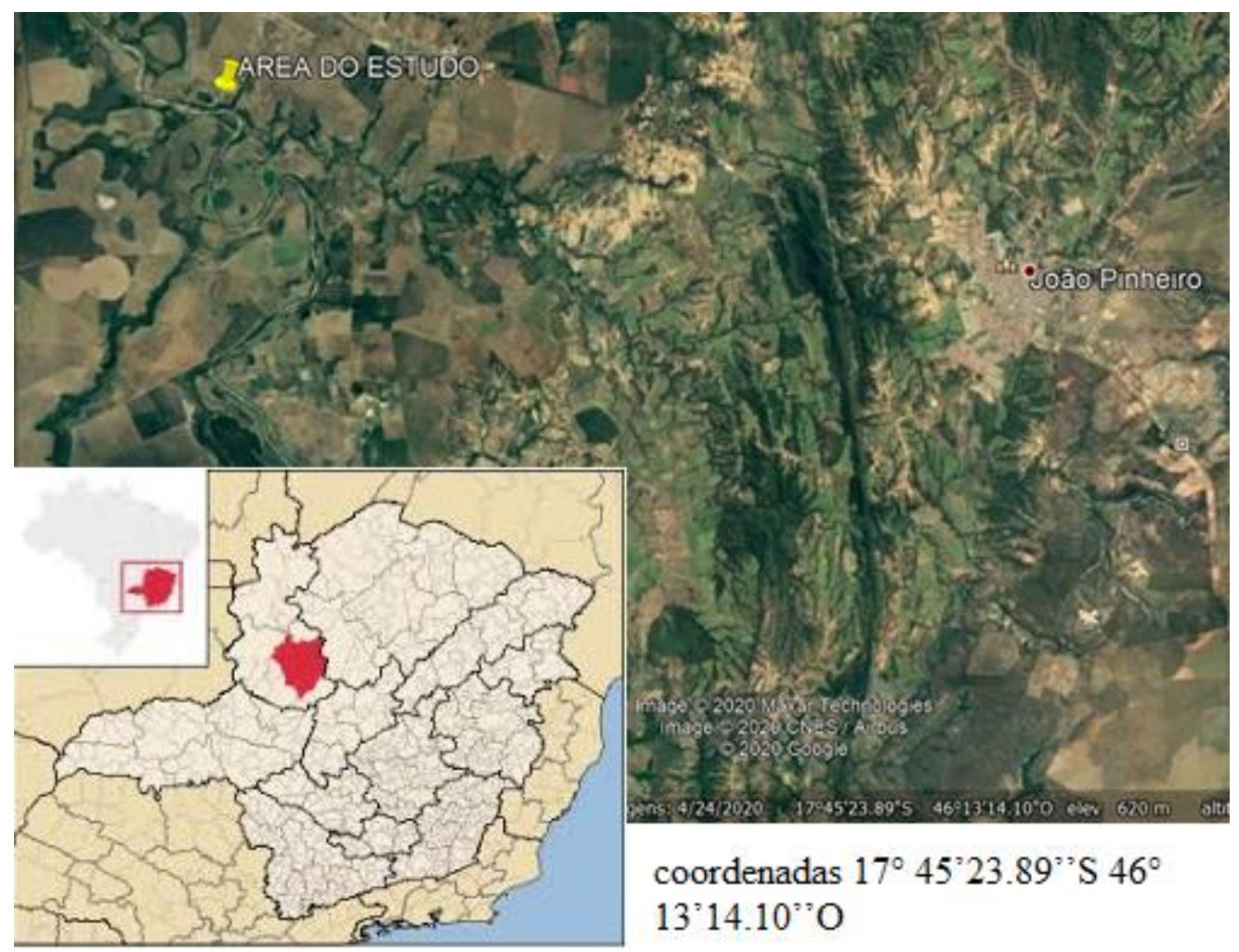

Fonte: Google Earth (2020) 


\section{RECIMA21 - REVISTA CIENTÍFICA MULTIDISCIPLINAR ISSN 2675-6218}

CONSERVAÇÃO DA BIODIVERSIDADE: LEVANTAMENTO DA FAUNA EM UMA ÁREA DE CERRADO NO MUNICÍPIO DE JOÃO PINHEIRO-MG, COMO FERRAMENTA DE ENSINO PARA EDUCAÇÃO AMBIENTAL Cássia Crisélem Lobo Moura, Keroly Cristine Soares de Oliveira, Wanderson Alves Pereira, Saulo Gonçalves Pereira

As amostragens foram realizadas em 03 (três) pontos fixos de observação, onde foram instaladas as armadilhas fotográficas (Camera Bushnell $®$ ), além de pontos variáveis de observação dos mamíferos. Os estudos foram procedidos em uma época do ano na qual a estação que se predominou foi a seca. As respectivas datas foram: início 14/08 à 11/09/2020.

$\mathrm{Na}$ tabela a seguir, são apresentadas as coordenadas geográficas de cada um dos pontos amostrais.

Tabela 1: Coordenadas e pontos da localização das câmeras do estudo.

\begin{tabular}{c|c|c}
\hline PONTO & \multicolumn{2}{|c}{ COORDENADAS } \\
\hline 01 & $17^{\circ} 43^{\prime} 50.78^{\prime \prime} \mathrm{S}$ & $46^{\circ} 18^{\prime} 48.74 " \mathrm{O}$ \\
\hline 02 & $17^{\circ} 43^{\prime} 52.45^{\prime \prime} \mathrm{S}$ & $46^{\circ} 18^{\prime} 46.80^{\prime \prime} \mathrm{O}$ \\
\hline 03 & $17^{\circ} 42^{\prime} 47.32^{\prime \prime} \mathrm{S}$ & $46^{\circ} 20^{\prime} 3.31^{\prime \prime} \mathrm{O}$ \\
\hline \multicolumn{3}{|c}{ Fonte: Google Earth }
\end{tabular}

Para o desenvolvimento dos estudos relacionados à fauna foram efetuados levantamentos de dados primários e secundários sobre a região, com enfoque direcionado à mastofauna.

Para auxílio à observação direta, utilizamos armadilhas fotográficas que ficaram expostas por 07 dias em cada ponto. Tais armadilhas fotográficas foram instaladas em trilhas e no meio da mata. Com a finalidade de atrair os animais para as câmeras foram expostas iscas (ceva) com frutas, sardinhas, milho, dentre outros alimentos olfativos (LUIZ et al., 2019).

Os levantamentos biológicos foram baseados no método de Avaliação Ecológica Rápida (AER) (SAYRE et al., 2003), por trilhas, avistamento e fotografias. Este método pode ser definido como [...] "uma rápida, porém eficiente caracterização dos tipos de fauna associadas. Desta forma, por serem ferramentas úteis para a conservação, as AER são cada vez mais utilizadas para a rápida caracterização da biodiversidade de uma área" (SAYRE et al., 2003, p. 06).

Os animais identificados foram classificados em níveis taxonômicos mais restritos possíveis; buscando-se, também, identificar espécies potencialmente ameaçadas de extinção, de acordo com a edição mais atualizada do livro Vermelho das espécies em extinção, e ainda de acordo com a classificação.

Os dados foram tabulados em planilhas do Microsoft Excel e depois transformados em tabelas e fotografias. Além da procura ativa por espécimes na natureza, foram consultados os moradores da região das áreas de influência e os funcionários da Fazenda, a fim de coletar informações sobre espécimes não encontradas durante o período de estudo. Essas informações foram organizadas para constituir a lista de espécies da área amostrada com dados tabulados como "informação". Ressalta-se que as informações não foram tomadas como entrevista, mas apenas como conversas informais. 


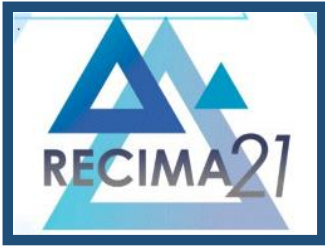

\section{RECIMA21 - REVISTA CIENTÍFICA MULTIDISCIPLINAR ISSN 2675-6218}

CONSERVAÇÃO DA BIODIVERSIDADE: LEVANTAMENTO DA FAUNA EM UMA ÁREA DE CERRADO NO MUNICÍPIO DE JOÃO PINHEIRO-MG, COMO FERRAMENTA DE ENSINO PARA EDUCAÇÃO AMBIENTAL Cássia Crisélem Lobo Moura, Keroly Cristine Soares de Oliveira, Wanderson Alves Pereira, Saulo Gonçalves Pereira

Posteriormente foi realizada a discussão à luz da literatura e, ainda a busca da relação dos achados com processos de Educação Ambiental dentro do que é preconizado na LDB, Temas Transversais e na BNCC.

Ressalta-se que tais procedimentos não requerem autorização de órgãos ambientais competentes, tendo em vista que os animais não foram manipulados e coletados e contou com a supervisão de biólogo sênior.

Por fim, a partir dos resultados elaborou-se uma cartilha educativa para ensino fundamental apresentando os animais identificados no estudo com a finalidade educativa para a questão ambiental (anexo 01). ]

Tabela 2- Imagens registradas durante o estudo, contendo o momento de instalação das câmeras, local e caminhada dos realizadores do estudo.

Figura 2- iscas prontas e câmera preparada

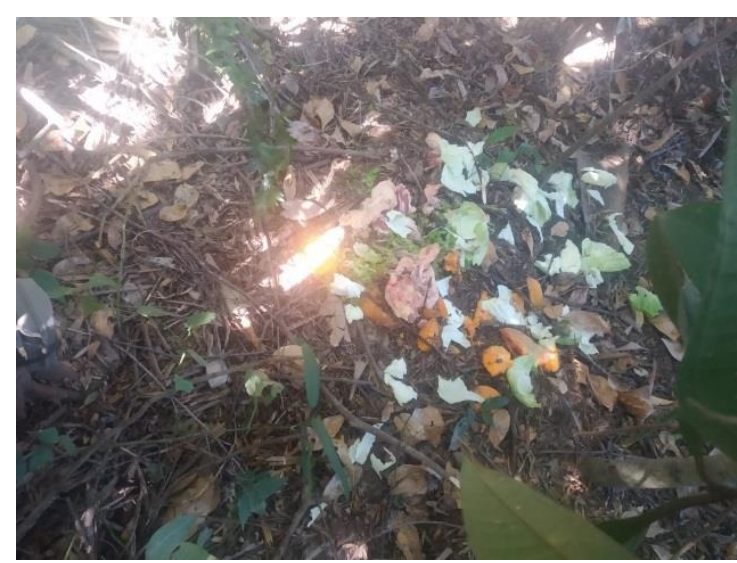

Fonte: arquivo pessoal (2020)

Figura 4- $2^{\circ}$ Ponto $\left(17^{\circ} 43^{\prime} 52.45^{\prime \prime} \mathrm{S}\right.$ $46^{\circ} 18^{\prime} 46.80^{\prime \prime}$ ) vereda

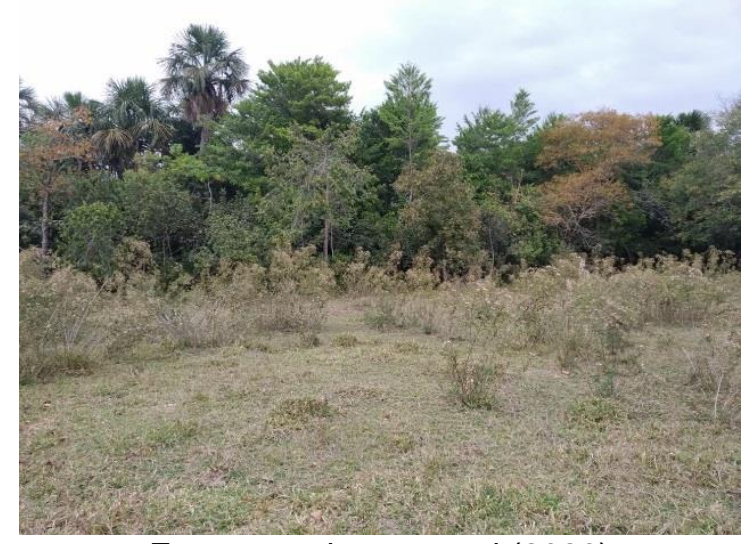

Fonte: arquivo pessoal (2020)
Figura 3- Instalando a $1^{\circ}$ câmera $1^{\circ}$ Ponto $\left(17^{\circ} 43^{\prime} 50.78^{\prime \prime} \mathrm{S} 46^{\circ} 18^{\prime} 48.74^{\prime \prime} 0\right)$

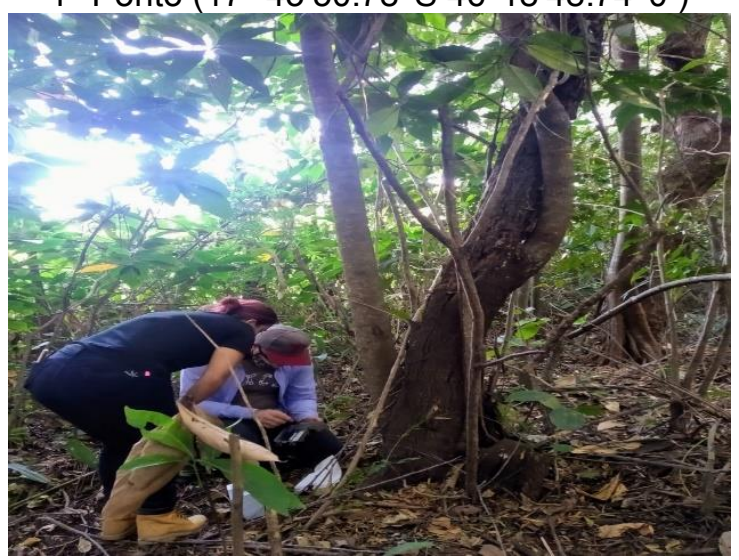

Fonte: arquivo pessoal (2020)

Figura 5- Preparação das iscas para $2^{\circ}$ ponto $\left(17^{\circ} 43^{\prime} 52.45^{\prime \prime} \mathrm{S} 46^{\circ} 18^{\prime} 46.80^{\prime \prime} \mathrm{)}\right)$

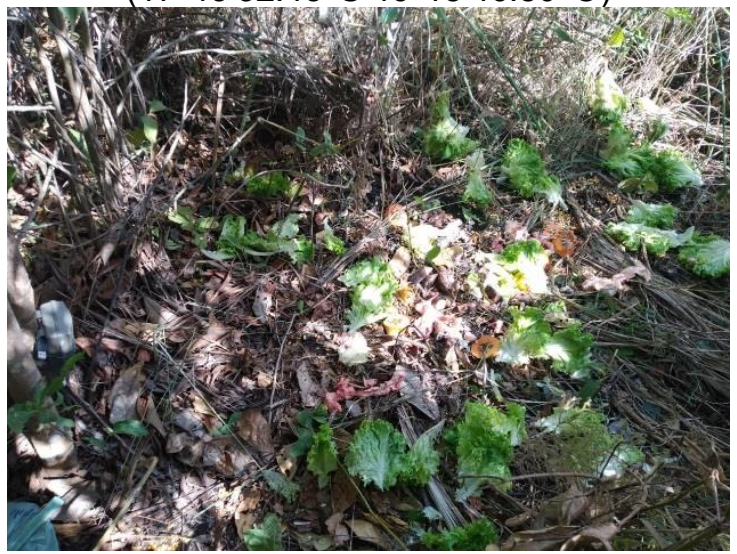

Fonte: arquivo pessoal (2020) 


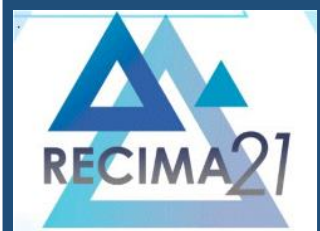

\section{RECIMA21 - REVISTA CIENTÍFICA MULTIDISCIPLINAR ISSN 2675-6218}

CONSERVAÇÃO DA BIODIVERSIDADE: LEVANTAMENTO DA FAUNA EM UMA ÁREA DE CERRADO NO MUNICÍPIO DE JOÃO PINHEIRO-MG, COMO FERRAMENTA DE ENSINO PARA EDUCAÇÃO AMBIENTAL
Figura 6- preparação das iscas para o $3^{\circ}$ ponto $\left(17^{\circ} 42^{\prime} 47.32^{\prime \prime} \mathrm{S} 46^{\circ} 20^{\prime} 3.31^{\prime \prime} \mathrm{O}\right)$

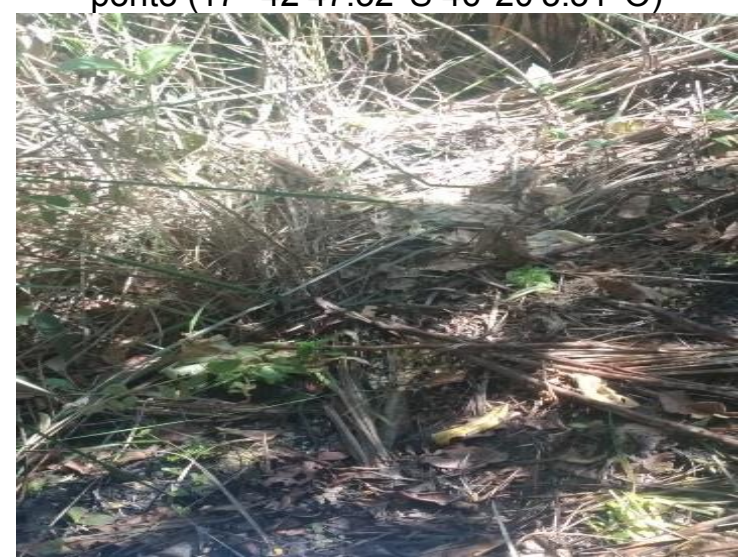

Fonte: arquivo pessoal (2020)
Figura 7- Câmera posicionada e preparada $2^{\circ}$ ponto $\left(17^{\circ} 43^{\prime} 52.45^{\prime \prime} \mathrm{S} 46^{\circ} 18^{\prime} 46.80^{\prime \prime} \mathrm{O}\right)$

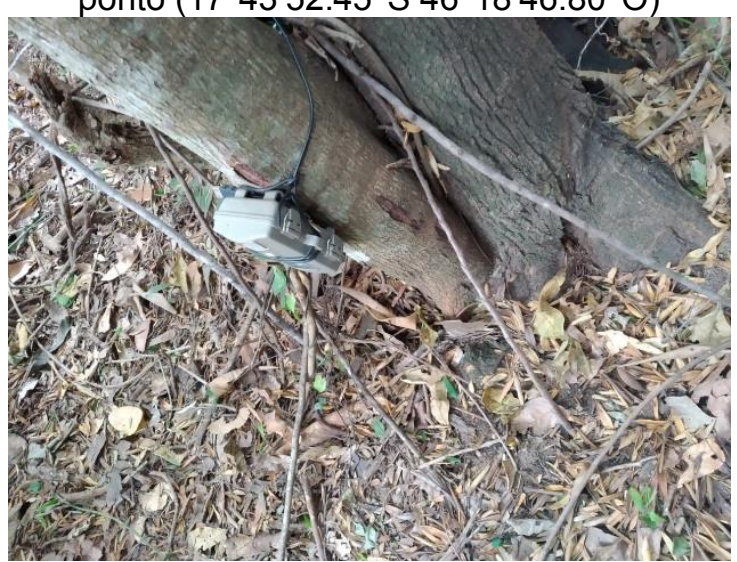

Fonte: arquivo pessoal (2020)

Figura 09- Imagem de dentro da vereda do $2^{\circ}$ ponto $\left(17^{\circ} 43^{\prime} 52.45^{\prime \prime} S 46^{\circ} 18^{\prime} 46.80^{\prime \prime} \mathrm{O}\right)$

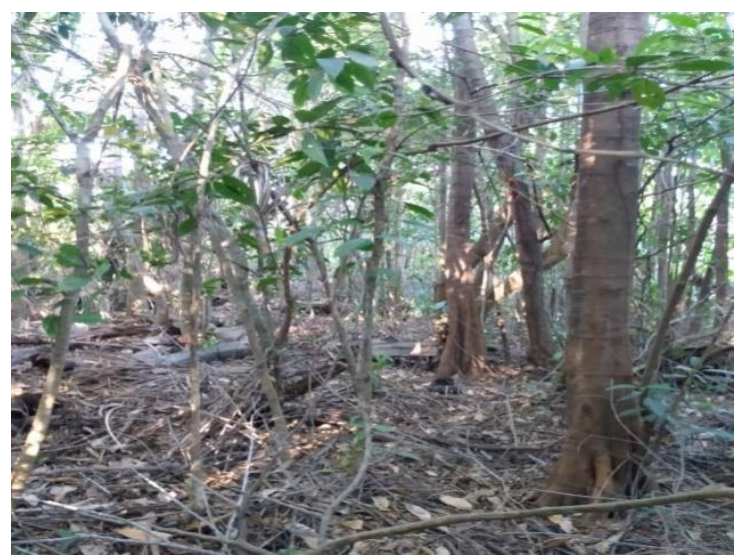

Fonte: arquivo pessoal (2020)

Figura 11 - Preparação da ceva (iscas)

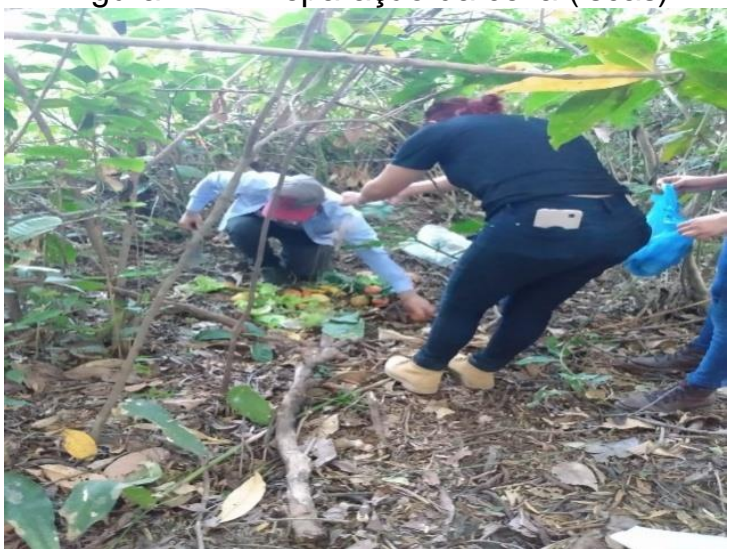

Fonte: arquivo pessoal (2020) 


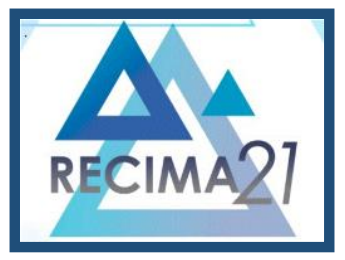

\section{RECIMA21 - REVISTA CIENTÍFICA MULTIDISCIPLINAR ISSN 2675-6218}

CONSERVAÇÃO DA BIODIVERSIDADE: LEVANTAMENTO DA FAUNA EM UMA ÁREA DE CERRADO NO MUNICÍPIO DE JOÃO PINHEIRO-MG, COMO FERRAMENTA DE ENSINO PARA EDUCAÇÃO AMBIENTAL Cássia Crisélem Lobo Moura, Keroly Cristine Soares de Oliveira, Wanderson Alves Pereira, Saulo Gonçalves Pereira

Figura 12- Caminhada sobre o local

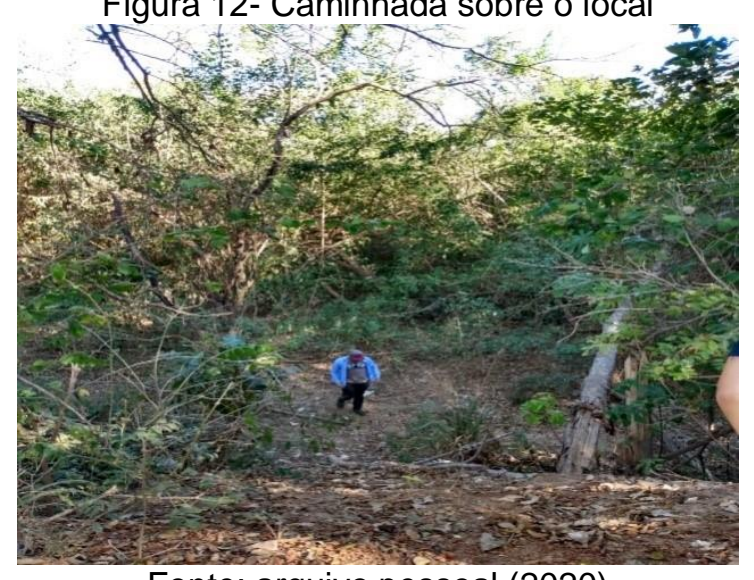

Fonte: arquivo pessoal (2020)
Figura 13- Caminhada sobre o local

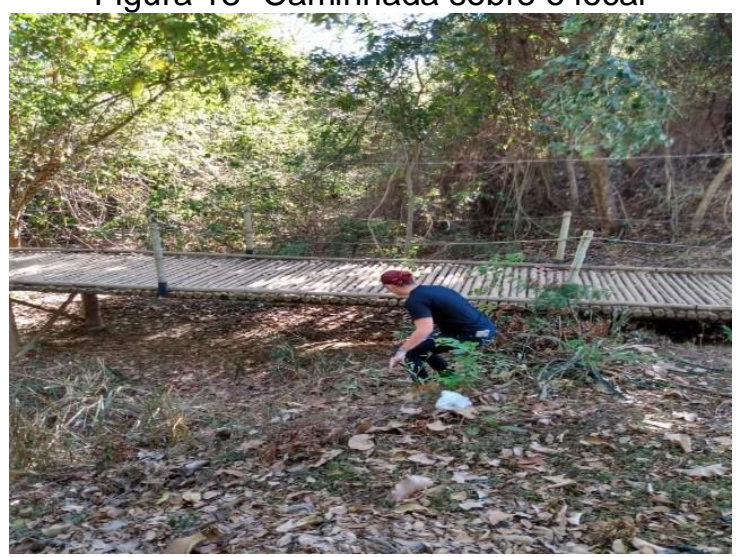

Fonte: arquivo pessoal (2020)

\section{FUNDAMENTAÇÃO TEÓRICA \\ CERRADO}

O Cerrado com sua grande extensão territorial é considerado portador de uma das maiores biodiversidades ecossistêmicas. É o segundo maior bioma da América do Sul, [...] "ocupando uma área de 2.036.448 ha, 22\% do território nacional, no qual encontram-se nascentes das três maiores bacias hidrográficas da América do Sul: Amazônica/Tocantins; São Francisco; e Prata" (BIZERRIL, 2009, p. 02). Por isso, o cerrado é de grande importância ambiental, social e econômica, e deve receber uma atenção maior tanto pública como política, com a oferta de programas que ajudem a lidar com a valorização da diversidade ecológica e recursos naturais juntamente com populações locais que utilizam do mesmo. "O termo Cerrado é utilizado para designar o conjunto de ecossistemas (savanas, matas, campos e matas de galeria) que ocorrem no Brasil Central” (EITEN, 1977, p.14). De acordo com o Ministério do Meio Ambiente - MMA:

"[...] o Cerrado tem grande importância social. Muitas populações sobrevivem de seus recursos naturais, incluindo etnias indígenas, quilombolas, geraizeiros, ribeirinhos, babaçueiras, vazanteiros e comunidades quilombolas que, juntas, fazem parte do patrimônio histórico e cultural brasileiro, e detêm um conhecimento tradicional de sua biodiversidade (BRASIL, 2011, p. 45).

Sendo assim, o Município de João Pinheiro, que pertence ao estado de Minas Gerais, encontra-se em uma área de cerrado que é denominada Planalto Central, na qual podemos notar um relevo suavizado resultante de vários ciclos erosionais, contando com cerrado no sentido restrito, pastagens, agricultura de sequeiro e irrigada, campo cerrado, matas e áreas de reflorestamento. As áreas que eram planas ou onduladas ganharam forma de pastagens e áreas de Reflorestamento (Eucalipto). Já as matas, denominadas ciliares, e as "veredas", estão presentes nas margens de córregos e nascentes onde há uma boa preservação (SAADI et al., 2005). 


\section{RECIMA21 - REVISTA CIENTÍFICA MULTIDISCIPLINAR ISSN 2675-6218}

CONSERVAÇÃO DA BIODIVERSIDADE: LEVANTAMENTO DA FAUNA EM UMA ÁREA DE CERRADO NO MUNICÍPIO DE JOÃO PINHEIRO-MG, COMO FERRAMENTA DE ENSINO PARA EDUCAÇÃO AMBIENTAL Cássia Crisélem Lobo Moura, Keroly Cristine Soares de Oliveira, Wanderson Alves Pereira, Saulo Gonçalves Pereira

Segundo Machado et al. (2004), o cerrado continua sendo destruído de forma progressiva. De acordo com análises dos satélites MODIS, durante o ano de 2002, sobressaiu que metade do cerrado já foi desmatado ou sofreu alterações pela ação humana. Levando o título de segundo bioma brasileiro com maiores alterações devido a atividades humanas, o cerrado sofre frequentemente mudanças com a exploração predatória de madeira para produção de carvão e aberturas de novas áreas para produção de grãos e criação de animais para produção de carnes, ou seja, seus recursos naturais estão sendo esgotados (BRASIL, 2011).

Por tudo isso, é importante conhecer sobre o cerrado e a sua diversidade, para estudar métodos de conservação e o que levará ao desenvolvimento do mesmo, sem sofrer impacto direto, que futuramente poderão ser notadas, levando a população a tomar um caminho com pesquisas mais orientadas para sua conservação (OLIVEIRA; MARQUIS, 2002).

\section{EDUCAÇÃO AMBIENTAL}

A origem da Educação Ambiental (EA) está ligada à criação da UNESCO, que ocorreu no ano de 1946, órgão da ONU que iniciou um debate voltado para a educação de modo geral e a EA. A criação desse órgão fez parte das iniciativas decorrentes do pós-guerra, para construir condições sociais e econômicas que validassem a paz duradoura (CARLOS; SILVA, 2011). Em 1968, em Paris, na Conferência sobre Biosfera, foi elaborado o programa Homem e Biosfera (MaB, do inglês Man and the Biosphere), no qual tinha o intuito de proporcionar uma boa relação entre a população e o meio ambiente no mundo, assim proporcionando um conhecimento que busca ampliar o entendimento e a prática dos valores humanos e o meio ambiente (CARLOS; SILVA, 2011).

Em Tbilisi (EUA), no ano de 1977, houve uma Conferência Intergovernamental a respeito da Educação Ambiental. Essa conferência ocorreu durante um período de 13 dias, no mês de outubro, e ficou conhecida como Conferência de Tbilisi, em que sucederam 41 recomendações sobre a EA. A declaração de Tbilisi indica um programa multidisciplinar de estudos ambientais ligados com essas profissões e relacionados a ambientes naturais e urbanos (CARLOS; SILVA (2011).

Já a Conferência de 1977 foi nada mais que uma continuação daquela que aconteceu em Estocolmo em 1972, o Programa Internacional de Educação Ambiental, que foi considerada como um ponto de partida, pois durante a Conferência foi determinado objetivos, princípios e estratégias da EA (PEREIRA, 2017).

A EA passou a ter mais importância após a conferência de Estocolmo e, posteriormente, houve a elaboração do Programa das Nações Unidas para o Meio Ambiente (Pnuma), que caminharia com a UNESCO dividindo as adversidades pertencentes a EA no âmbito das nações unidas. A UNESCO e a Pnuma criaram o Programa Internacional de EA (Piea) para promover a troca de ideias, informações, experiências, entre outras questões sobre a EA, nas nações de todo o mundo. Em 1975, a Piea realizou seu primeiro Seminário Internacional onde foi aprovada a Carta de 


\section{RECIMA21 - REVISTA CIENTÍFICA MULTIDISCIPLINAR ISSN 2675-6218}

CONSERVAÇÃO DA BIODIVERSIDADE: LEVANTAMENTO DA FAUNA EM UMA ÁREA DE CERRADO NO MUNICÍPIO DE JOÃO PINHEIRO-MG, COMO FERRAMENTA DE ENSINO PARA EDUCAÇÃO AMBIENTAL

Belgrado, que estabelecia metas básicas da ação ambiental (CARLOS; SILVA, 2011). A Carta de Belgrado estabeleceu objetivos para a Educação Ambiental, que são:

1. Conscientização: contribuir para que indivíduos e grupos adquiram consciência e sensibilidade em relação ao meio ambiente como um todo e quanto aos problemas relacionados com ele.

2. Conhecimento: propiciar uma compreensão básica sobre o meio ambiente, principalmente quanto às influências do ser humano e de suas atividades.

3. Atitudes: propiciar a aquisição de valores e motivação para induzir uma participação ativa na proteção ao meio ambiente e na resolução dos problemas ambientais.

4. Habilidades: proporcionar condições para que os indivíduos e grupos sociais adquiram as habilidades necessárias a essa participação ativa.

5. Capacidade de avaliação: estimular a avaliação das providências efetivamente tomadas em relação ao meio ambiente e aos programas de educação ambiental.

6. Participação: contribuir para que os indivíduos e grupos desenvolvam o senso de responsabilidade e de urgência com relação às questões ambientais (CARLOS; SILVA, 2011, p. 55 e 56).

Atualmente, devido ao aumento populacional, especialmente nos centros urbanos, tem ocorrido um acréscimo significativo dos impactos ambientais. Isso se deve em parte a atitudes irresponsáveis e a falta de consciência ambiental por grande parte da população perante seu consumo e descarte de resíduos. Fatos como esses apontam os desafios e a necessária mudança nas formas de pensar e agir sobre as questões ambientais (JACOBI, 2003).

Um dos processos educativos é a Educação Ambiental, pois possibilita a formação de cidadãos com conhecimentos a respeito do ambiente e de seus problemas associados, ou seja, é um processo que leva os indivíduos a reconhecerem valores, entenderem conceitos, desenvolverem aptidões e atitudes para compreenderem e respeitarem as inter-relações dos seres com o meio ambiente (ADELITA, et al., 2010, p. 6). No dia 17 abril de 1999, a Educação Ambiental tornou-se lei (9.795/99):

A Lei N 9.795 - Lei da Educação Ambiental, em seu Art. $2^{\circ}$ afirma: "A educação ambiental é um componente essencial e permanente da educação nacional, devendo estar presente, de forma articulada, em todos os níveis e modalidades do processo educativo, em caráter formal e não formal". O artigo $3^{\circ}$, inciso II, complementa a ideia ao prescrever que cabe às "instituições educativas promover a educação ambiental de maneira integrada aos programas educacionais que desenvolvem" (BRASILIA, 2007, p.19).

Segundo Jacobi (2003), o ecossistema requer uma reflexão das práticas sociais (pois há uma grande degradação do meio ambiente), que envolva necessariamente a EA em um processo educativo que abrange uma equipe de responsáveis do âmbito educativo, atuando numa perspectiva interdisciplinar. $\mathrm{O}$ autor destaca ainda que as inter-relações entre o meio natural e social devem caminhar juntas e produzir conhecimento para a preservação do meio.

Em 1998 foram apresentados os PCN's, no qual articulou que o meio ambiente deve ser tratado de forma transversal nas escolas e que desenvolvam comportamentos "ambientalmente 


\section{RECIMA21 - REVISTA CIENTÍFICA MULTIDISCIPLINAR ISSN 2675-6218}

CONSERVAÇÃO DA BIODIVERSIDADE: LEVANTAMENTO DA FAUNA EM UMA ÁREA DE CERRADO NO MUNICÍPIO DE JOÃO PINHEIRO-MG, COMO FERRAMENTA DE ENSINO PARA EDUCAÇÃO AMBIENTAL Cássia Crisélem Lobo Moura, Keroly Cristine Soares de Oliveira, Wanderson Alves Pereira, Saulo Gonçalves Pereira

corretos" que serão aprendidos na prática do dia a dia na escola: gestos de solidariedade, hábitos de higiene pessoal e dos diversos ambientes, e além de conceitos, a escola se proponha a trabalhar com atitudes, com formação de valores, com o ensino e a aprendizagem de habilidades e procedimentos (BRASILIA, 1998).

De acordo com os PCN's, a EA é desenvolvida para conscientizar e ajudar que novos pontos de vistas e posturas sejam adquiridos com a EA. Essa medida conduz a uma visão global do ambiente em que se vive, porém é de extrema necessidade que envolva toda a comunidade escolar nas ações formais, e toda a comunidade (população nas ações informais fora da escola), mas que também tem um objetivo de preconizar a relevância da educação ambiental no nosso cotidiano (BRASILIA, 2007). Portanto, a Educação Ambiental é de grande importância, pois contribui direta e indiretamente para adquirir conhecimentos e conscientizar a população de sua importância e cuidados com o meio.

\subsection{LEVANTAMENTO DE FAUNA}

Para conseguir levar a Educação Ambiental adiante é necessário conhecer o nosso meio ambiente. Nesse sentido, um levantamento da fauna da região é importante, sendo a principal ferramenta para promover o estudo e a conscientização (STOHLGREN et al., 1995). Pensando nessas medidas, o Programa de Avaliação Biológica Rápida opera coletando, analisando e disseminando informações que podem ser úteis para a conservação da biodiversidade. De acordo com BRASIL (2011, p.10):

Uma Avaliação Ecológica Rápida de uma área ou região terrestre é um levantamento flexível, acelerado e direcionado das espécies e tipos vegetacionais. As AER utilizam uma combinação de imagens de sensoreamento remoto, sobrevoos de reconhecimento, coletas de dados de campo e visualização de informação espacial para gerar informações úteis para o planejamento da conservação em múltiplas escalas.

Segundo Silveira et al. (2010), existem diferentes procedimentos para se produzir um levantamento de fauna, que seria de uma forma direta que procura mostrar partes importantes da diversidade animal que se relaciona com o bioma de cada localidade em um determinado tempo. Embora seja difícil fazer uma amostragem exata da diversidade encontrada.

De acordo com o conceito de Silveira et al. (2010), existem diferentes técnicas atualmente utilizadas para se inventariar a fauna e são as formas mais diretas para se acessar parte dos componentes da diversidade animal em um bioma ou localidade, em um determinado espaço e tempo. Assim:

Os resultados de qualquer amostragem constituem-se no somatório da(s) técnica(s) utilizada(s), da habilidade de quem conduz o inventário em detectar os organismos no espaço amostral e do componente temporal, expresso tanto em razão das horas 


\section{RECIMA21 - REVISTA CIENTÍFICA MULTIDISCIPLINAR ISSN 2675-6218}

CONSERVAÇÃo DA BIODIVERSIDADE: LEVANTAMENTO DA FAUNA EM UMA ÁREA DE CERRADO NO MUNICÍPIO DE JOÃO PINHEIRO-MG, COMO FERRAMENTA DE ENSINO PARA EDUCAÇÃO AMBIENTAL Cássia Crisélem Lobo Moura, Keroly Cristine Soares de Oliveira, Wanderson Alves Pereira, Saulo Gonçalves Pereira gastas em campo quanto da própria composição histórica da fauna, que, naturalmente, vai variar entre as localidades (SILVEIRA et al., 2010).

Pardini et al. (2003) já se baseavam na importância do inventariamento da fauna fundamentando a importância ecológica do grupo, principalmente de mamíferos, que ressaltava na introdução de desenvolvimento que afeta diretamente no habitat do animal. Os mesmos autores contam com várias técnicas atualizadas para se trabalhar com o monitoramento de fauna.

O conhecimento do meio natural e do ecossistema com o auxílio de levantamentos é de extrema importância no desenvolvimento de modelos de recuperação e Educação Ambiental (ALMEIDA, 2000). Pensando assim, existem vários métodos de levantamento de fauna e para se obter um resultado consideravelmente positivo é importante observar o horário escolhido para se realizar o levantamento, pois ele pode influenciar diretamente nos resultados. Os pontos de acesso têm grandes vantagens e desvantagens, dependendo da situação, por isso de acordo com Nunes e Betini (2002) esse processo deve ser levado em consideração para acessar a área para o monitoramento. Já Peixoto et al. (2007) sugerem o uso de alguns equipamentos que facilitam no monitoramento. Dentre eles estão: filmadora, câmera digital e binóculos.

As armadilhas fotográficas, por sua vez, vêm ganhando espaço no meio de vários métodos de amostragem para inventário. Segundo o estudo de Srbek-Araujo e Chiarello (2005), os resultados foram satisfatórios a longo e curto prazo, podendo ser um método único. Porém, Voss e Emmons (1996) afirmam que deve se associar outras técnicas para se obter bons dados para um levantamento de fauna.

Contudo, deve-se observar o local e a melhor forma de estratégia que podem se enquadrar para o habitat em questão, levando em conta o táxon a ser feito, o levantamento e o que melhor se adéqua ao pesquisador.

\section{ANÁLISE DE DADOS}

Com o material devidamente identificado, durante o período amostrado, foram registradas 23 espécies; sendo 04 répteis, 09 aves e 10 mamíferos. Todavia para que o estudo e seus resultados fossem garantidos, os animais dentre os quais tiveram o registro repetido no mesmo ponto foram considerados os mesmos dados. De acordo com Tobler, algumas espécies de mamíferos permanecem por longos períodos em frente às câmeras, por isso adotamos essa estratégia, para que os registros não ficassem repetidos. Como informação dos moradores locais foram elencadas 23 espécies (TOBLER et al.,2008).

O número relativamente baixo de espécies encontradas pode ser explicado pelo curto período no qual a pesquisa foi realizada, tendo em vista que a coleta de dados foi realizada em 03 semanas. Outra possibilidade pode ser que as câmeras foram instaladas em apenas 03 pontos 


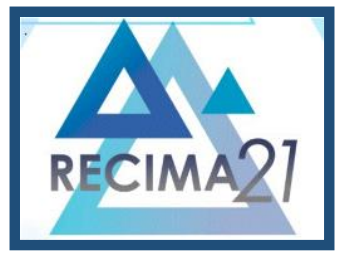

\section{RECIMA21 - REVISTA CIENTÍFICA MULTIDISCIPLINAR ISSN 2675-6218}

CONSERVAÇÃO DA BIODIVERSIDADE: LEVANTAMENTO DA FAUNA EM UMA ÁREA DE CERRADO NO MUNICÍPIO DE JOÃO PINHEIRO-MG, COMO FERRAMENTA DE ENSINO PARA EDUCAÇÃO AMBIENTAL Cássia Crisélem Lobo Moura, Keroly Cristine Soares de Oliveira, Wanderson Alves Pereira, Saulo Gonçalves Pereira

amostrais e próximo à fazenda, no qual a movimentação de animais selvagens é relativamente menor e há a presença do cão doméstico, o que pode espantar os animais (JUAREZ,2008).

Grande parte das espécies registradas no estudo possuem ampla distribuição geográfica das quais são endêmicas também do Cerrado. Curiosamente as espécies que se beneficiam e tendem a se tornar mais abundantes são aquelas mais generalistas, ou seja, as que ocupam diferentes nichos ecológicos, com maior flexibilidade de ocupação (AGNELLO, 2007; RICKLEFS, 2011).

Das espécies registradas no local do estudo de acordo com o Livro Vermelho das Espécies Ameaçadas de Extinção (BRASIL, 2011), foram registradas 05 espécies consideradas como vulneráveis (VU) de acordo com a IUCN Red List of Threatened Species. Version (2019): Raposa do campo - (Lycalopex vetulus); o Guariba - (Alouta. Guariba); Arara de barriga amarela (Ara. Ararauna), e a Anta (Tapires terrestris). A Jaguatirica (Lepardus $s p$ ) é considerado endêmica (EN) em Minas Gerais, porém vulnerável (VU). Sendo que, dessas espécies mencionadas, apenas a Raposa do Campo e a Jaguatirica foram fotografadas e registradas como Visualização Direta (VD), os outros foram registrados como Visualização Indireta (VI) ou Informação (INF).

Como "informação" (INF) os moradores da região informaram que nas proximidades existe a presença da Anta (Tapirus terrestris) que hoje também é considerada Vulnerável (IUCN, 2019). Os outros animais registrados não se encontram no Livro Vermelho das Espécies Ameaçadas de Extinção, no bioma do Cerrado (BRASIL, 2011).

Tabela 4 - Imagens registradas durante o campo

Figura 14 - Mimus sp (sabiá)

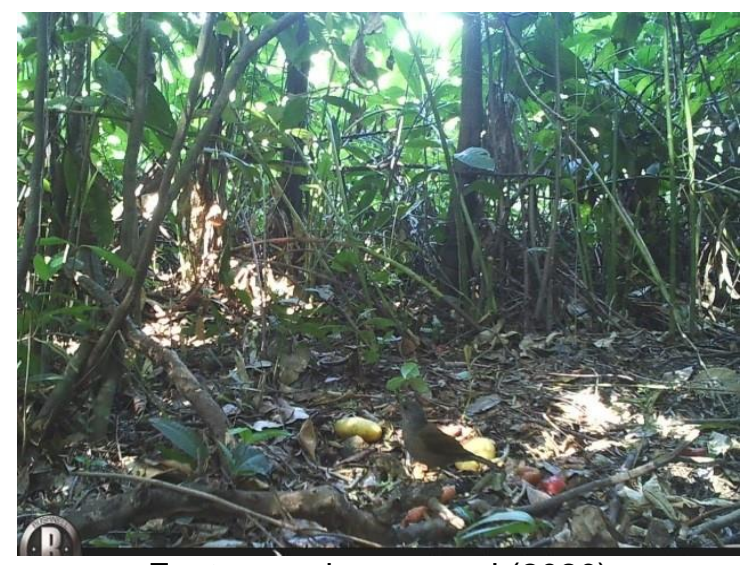

Fonte: arquivo pessoal (2020)
Figura 15 - D. albiventris (gambá-de orelhabranca)

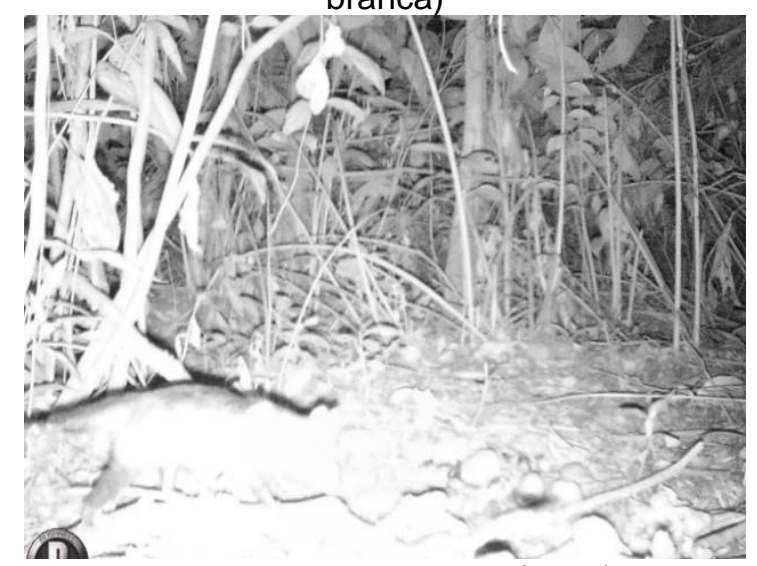

Fonte: arquivo pessoal (2020) 


\section{RECIMA21 - REVISTA CIENTÍFICA MULTIDISCIPLINAR ISSN 2675-6218}

CONSERVAÇÃO DA BIODIVERSIDADE: LEVANTAMENTO DA FAUNA EM UMA ÁREA DE CERRADO NO MUNICÍPIO DE JOÃO PINHEIRO-MG, COMO FERRAMENTA DE ENSINO PARA EDUCAÇÃO AMBIENTAL Cássia Crisélem Lobo Moura, Keroly Cristine Soares de Oliveira, Wanderson Alves Pereira, Saulo Gonçalves Pereira

Figura 16 - Dasypus novemcinctus (tatu galinha)

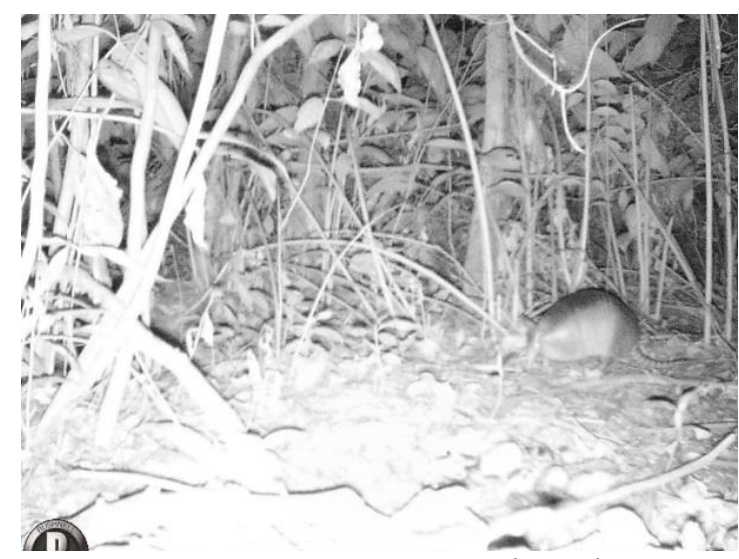

Fonte: arquivo pessoal (2020)
Figura 17 - D. albiventris (gambá-de orelhabranca)

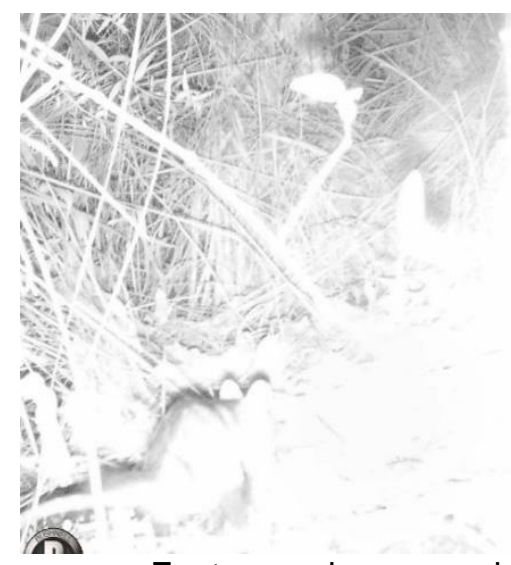

Fonte: arquivo pessoal (2020)

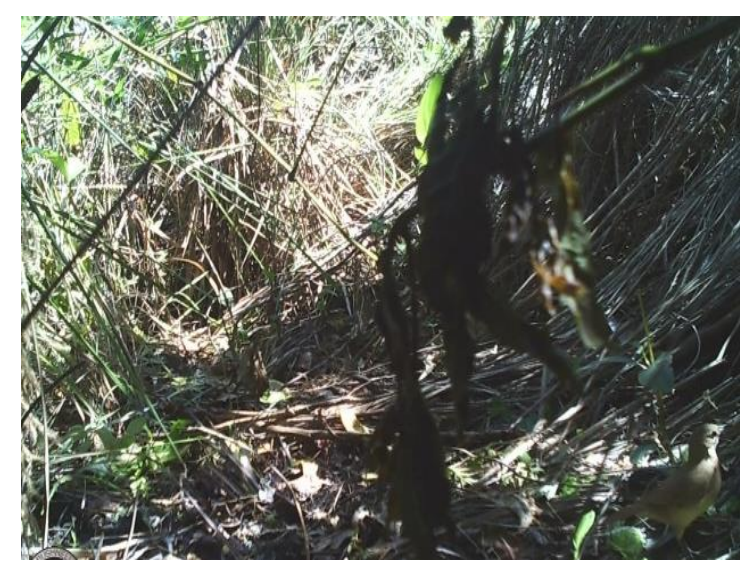

Fonte: arquivo pessoal (2020)
Figura 19 - A. cajaneus (saracura-três-potes)

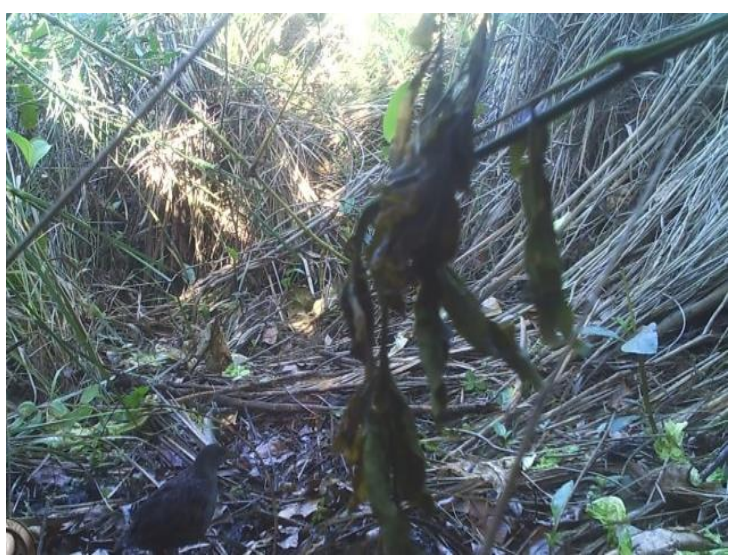

Fonte: arquivo pessoal (2020) 


\section{RECIMA21 - REVISTA CIENTÍFICA MULTIDISCIPLINAR ISSN 2675-6218}

CONSERVAÇÃO DA BIODIVERSIDADE: LEVANTAMENTO DA FAUNA EM UMA ÁREA DE CERRADO NO MUNICÍPIO DE JOÃO PINHEIRO-MG, COMO FERRAMENTA DE ENSINO PARA EDUCAÇÃO AMBIENTAL Cássia Crisélem Lobo Moura, Keroly Cristine Soares de Oliveira, Wanderson Alves Pereira, Saulo Gonçalves Pereira

Figura 20 - Coragyps atratus ( urubu-decabeça-pre-ta )

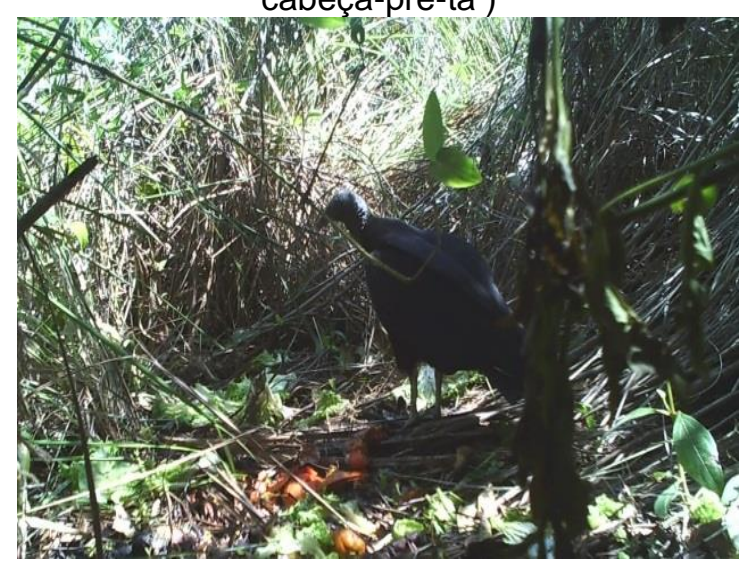

Fonte: arquivo pessoal (2020)
Figura 21 -Lycalopex vetulus (Raposa-docampo, raposinha)

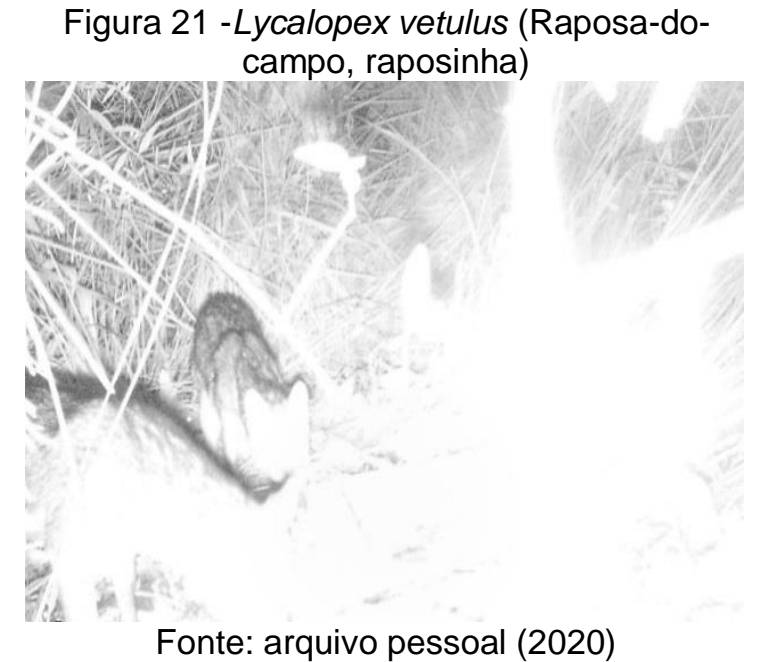

Fonte: arquivo pessoal (2020)

Figura 23 - Dasypus novemcinctus (tatu galinha)

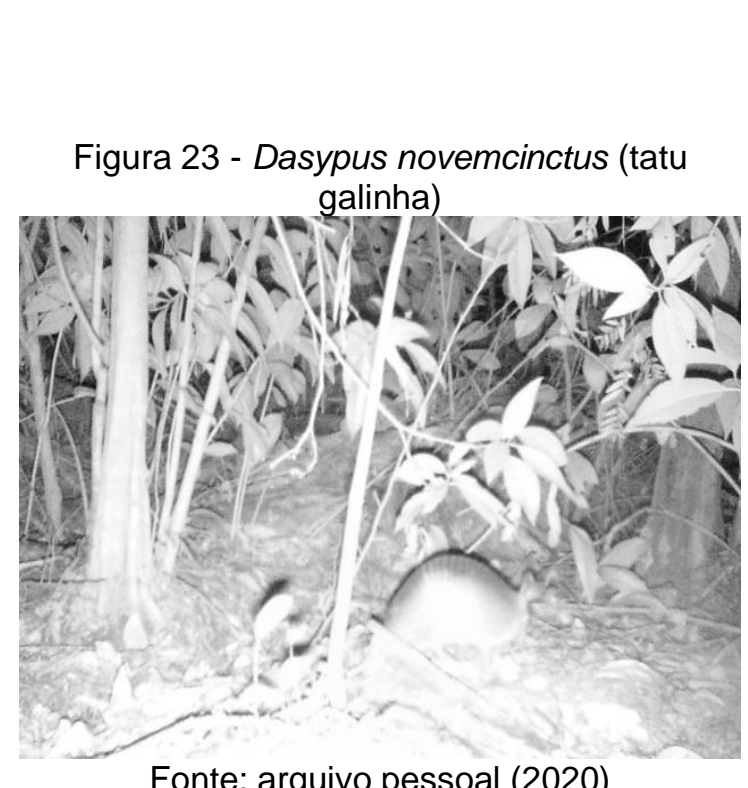

Fonte: arquivo pessoal (2020)

(1)

Fonte: arquivo pessoal (2020)

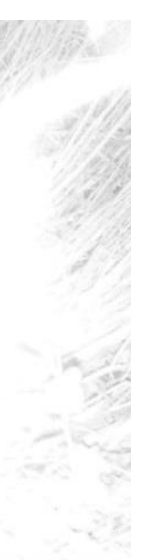




\section{RECIMA21 - REVISTA CIENTÍFICA MULTIDISCIPLINAR ISSN 2675-6218}

CONSERVAÇÃO DA BIODIVERSIDADE: LEVANTAMENTO DA FAUNA EM UMA ÁREA DE CERRADO NO MUNICÍPIO DE JOÃO PINHEIRO-MG, COMO FERRAMENTA DE ENSINO PARA EDUCAÇÃO AMBIENTAL Cássia Crisélem Lobo Moura, Keroly Cristine Soares de Oliveira, Wanderson Alves Pereira, Saulo Gonçalves Pereira

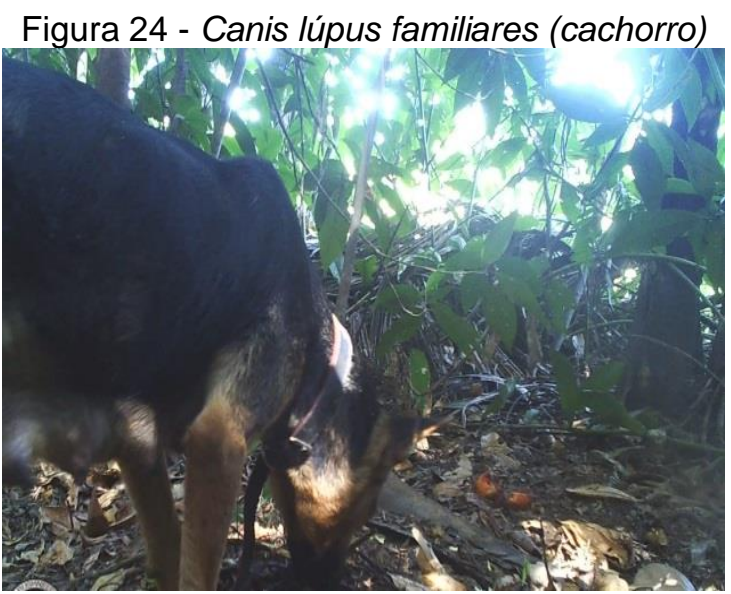

Fonte: arquivo pessoal (2020)
Figura 25 - Tupinambis Teguixin ( teiú, tiú)

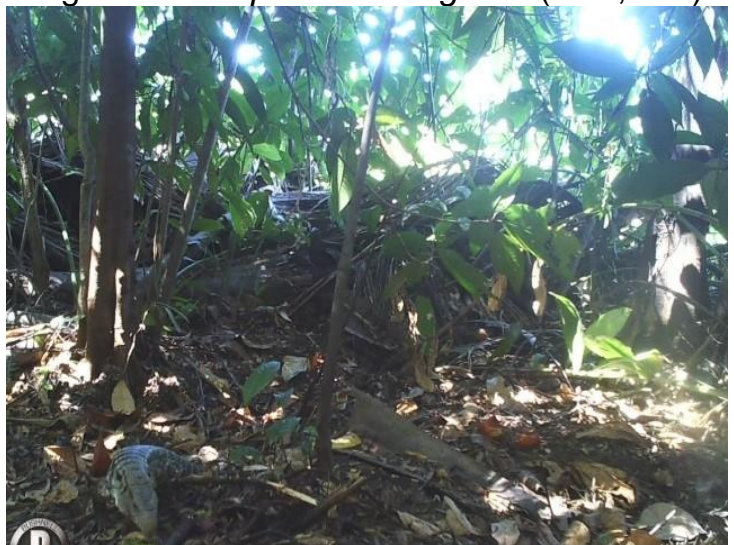

Fonte: arquivo pessoal (2020)

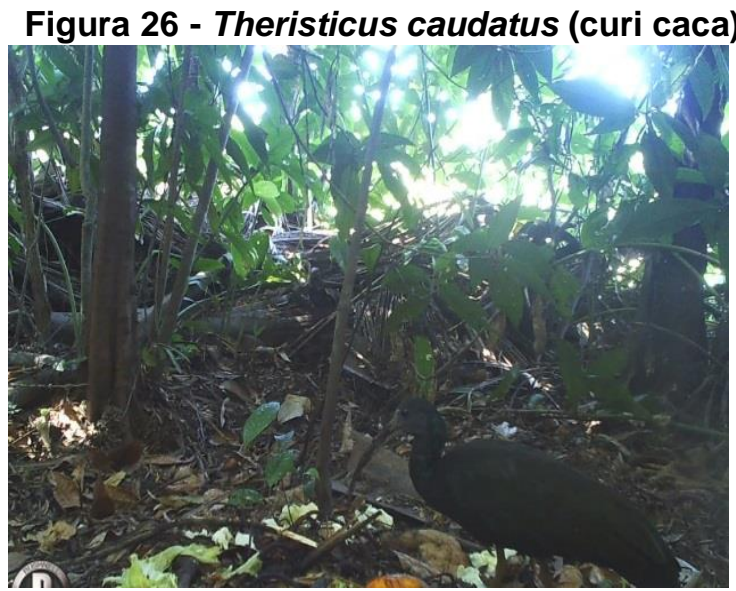

Fonte: arquivo pessoal (2020)

Como observado acima, nas imagens, foram capturadas fotos de várias espécies, tanto durante o dia quanto a noite. Algumas espécies de rápida e fácil identificação, outras exigiram maior detalhamento. 


\section{RECIMA21 - REVISTA CIENTÍFICA MULTIDISCIPLINAR ISSN 2675-6218}

CONSERVAÇÃO DA BIODIVERSIDADE: LEVANTAMENTO DA FAUNA EM UMA ÁREA DE CERRADO NO MUNICÍPIO DE JOÃO PINHEIRO-MG, COMO FERRAMENTA DE ENSINO PARA EDUCAÇÃO AMBIENTAL Cássia Crisélem Lobo Moura, Keroly Cristine Soares de Oliveira, Wanderson Alves Pereira, Saulo Gonçalves Pereira

Quadro 01 - Relação das espécies, classe, ordem, família, espécie, nome popular, estado de conservação, tipo de visualização, campanha, registrados durante o período do estudo

\begin{tabular}{|c|c|c|c|c|c|c|}
\hline Classe & Ordem & Família & Espécie & Nome Popular & $\begin{array}{c}\text { Estado de } \\
\text { Conser- } \\
\text { vação }\end{array}$ & $\begin{array}{l}\text { Tipo de } \\
\text { visuali- } \\
\text { zação }\end{array}$ \\
\hline \multirow{4}{*}{ Répteis } & Squamata & Teiidae & $\begin{array}{l}\text { Tupinambis } \\
\text { Teguixin }\end{array}$ & Teiú, tiú & LC & VD \\
\hline & Escamados & Tropiduridae & Tropidus Torquato & Lagarto & LC & INF \\
\hline & Squamata & Viperidae & Crotalus durissus & Cascavel & LC & INF \\
\hline & Squamata & Boidae & Boa constrictor & Jiboia & LC & INF \\
\hline \multirow{10}{*}{ Aves } & Pelecaniformes & Threskiornithidae & $\begin{array}{l}\text { Theristicus } \\
\text { caudatus }\end{array}$ & Curicaca & LC & VD \\
\hline & Passeriformes & Mimidae & Mimus sp & Sabiá & LC & VD \\
\hline & Cathartiformes & Cathartidae & Coragyps atratus & $\begin{array}{l}\text { Urubu-de- } \\
\text { cabeça-preta }\end{array}$ & LC & VD \\
\hline & Psittaciformes & Psitacidae & Ara. ararauna & Arara-amarela & VU & VI \\
\hline & Gruiformes & Rallidae & $\begin{array}{l}\text { Aramides. } \\
\text { cajaneus }\end{array}$ & $\begin{array}{l}\text { Saracura-três- } \\
\text { potes }\end{array}$ & LC & VD \\
\hline & Psittaciformes & Psittacidae & Brotogeris tirica & Periquito & LC & INF \\
\hline & $\underline{\text { Rheiformes }}$ & $\underline{\text { Rheidae }}$ & Rhea. americana & Ema & LC & INF \\
\hline & \multirow[t]{2}{*}{$\underline{\text { Passeriformes }}$} & Corvidae & $\begin{array}{c}\text { Cyanocorax } \\
\text { chrysops }\end{array}$ & Gralha & LC & INF \\
\hline & & Furnariidae & Furnariu. rufus & João de barro & LC & INF \\
\hline & $\underline{\text { Primates }}$ & Callitrichidae & $\begin{array}{l}\text { Callithrix } \\
\text { penicillata }\end{array}$ & $\begin{array}{l}\text { Miquinho- } \\
\text { Sagui }\end{array}$ & LC & VI \\
\hline
\end{tabular}




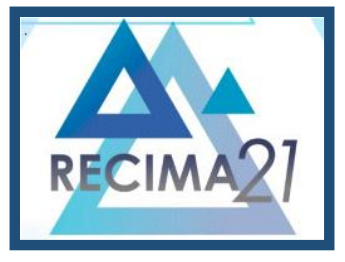

\section{RECIMA21 - REVISTA CIENTÍFICA MULTIDISCIPLINAR ISSN 2675-6218}

CONSERVAÇÃo DA BIODIVERSIDADE: LEVANTAMENTO DA FAUNA EM UMA ÁREA DE CERRADO NO MUNICÍPIO DE JOÃO PINHEIRO-MG, COMO FERRAMENTA DE ENSINO PARA EDUCAÇÃO AMBIENTAL Cássia Crisélem Lobo Moura, Keroly Cristine Soares de Oliveira, Wanderson Alves Pereira, Saulo Gonçalves Pereira

\begin{tabular}{|c|c|c|c|c|c|c|}
\hline \multirow{9}{*}{ Mammalia } & Primatas & Atelidae & Alouta. guariba & Guariba & VU & VI \\
\hline & Cingulata & Dasypodidae & $\begin{array}{c}\text { Dasypus } \\
\text { novemcinctus }\end{array}$ & Tatu galinha & LC & VD \\
\hline & Didelphimorphia & Didelphidae & $\begin{array}{l}\text { Didelphis. } \\
\text { albiventris }\end{array}$ & $\begin{array}{c}\text { Gambá-de } \\
\text { orelha-branca }\end{array}$ & LC & VD \\
\hline & \multirow{3}{*}{ Carnivora } & Felidae & Lepardus sp & Jaguatirica & VU & VD \\
\hline & & Canidae & Lycalopex vetulus & $\begin{array}{l}\text { Raposa-do- } \\
\text { campo, } \\
\text { raposinha, }\end{array}$ & VU & VD \\
\hline & & Canidae & $\begin{array}{l}\text { Canis lúpus } \\
\text { familiares }\end{array}$ & Cão domestico & LC & VD \\
\hline & Perissodactyla & Tapiridae & Tapirus terrestris & Anta & VU & INF \\
\hline & Erinaceomorpha & Erinaceidae & $\begin{array}{l}\text { Erinaceus } \\
\text { europaeus }\end{array}$ & $\begin{array}{l}\text { Ouriço- } \\
\text { cacheiro }\end{array}$ & LC & INF \\
\hline & Carnivora & $\underline{\text { Canidae }}$ & Cerdocyon thous & $\begin{array}{c}\text { Cachorro do } \\
\text { mato }\end{array}$ & LC & INF \\
\hline
\end{tabular}

Legenda: VD - visualização direta; VI - visualização indireta; INF- informação; Seca- SE; Chuvosa $\mathrm{CH}$; quase ameaçada (NT); Pouco preocupante (LC); Vulnerável VU;

A partir de agora serão apresentadas as espécies, separadas pelos grupos faunísticos, registradas durante o estudo e suas características comuns.

\section{HERPERTOFAUNA}

De acordo com Lima et al. (2016) os termos usados em ecologia, Herpetofauna é um conjunto das espécies de répteis e anfíbios que vivem em uma determinada região. Existem no Brasil atualmente 946 táxons de anfíbios e 744 de répteis (SEGALLA et al. 2012). Dentre as espécies brasileiras que se encontram na lista nacional (BRASIL, 2008) e internacional (IUCN 2019) de espécies ameaçadas de extinção, pelo menos 90 constam como "Deficientes em Dados" (DD); o que mostra a falta de informações sobre o grupo em todo o país, e que sendo contrária essa realidade, ajudaria na manutenção da espécie. A seguir listam-se a caracterização de cada uma das espécies visualizadas.

Teiú (Tupinambis Teguixin): O Teiú é considerado incomum e diferente dos demais lagartos por possuir a dentição caracterizada pela heterodontia, gosta de se esconder em tocas e buracos é considerado por muitos um empecilho por comer os ovos de galinhas (BRASIL, 2011). 


\section{RECIMA21 - REVISTA CIENTÍFICA MULTIDISCIPLINAR ISSN 2675-6218}

CONSERVAÇÃO DA BIODIVERSIDADE: LEVANTAMENTO DA FAUNA EM UMA ÁREA DE CERRADO NO MUNICÍPIO DE JOÃO PINHEIRO-MG, COMO FERRAMENTA DE ENSINO PARA EDUCAÇÃO AMBIENTAL Cássia Crisélem Lobo Moura, Keroly Cristine Soares de Oliveira, Wanderson Alves Pereira, Saulo Gonçalves Pereira

Lagarto (Tropidus Torquato): Presente em todos os biomas do Brasil o Lagarto habita diferentes ambientes e substratos, podendo ser terrícolas, fossoriais (galerias no subsolo), saxícolas (associados às rochas), arborícolas e semiaquáticos. Eles possuem diferentes hábitos diurno ou noturno. Dependendo de sua espécie, são onívoros, mas alimentam-se preferencialmente de invertebrados, principalmente de artrópodes (ICMBIO, 2014).

Cascavel (Crotalus durissus): A Cascavel é uma cobra venenosa e no Brasil é encontrada uma espécie que possui veneno neurotóxico. Esse veneno atua no sistema nervoso da vítima dificultando sua locomoção e respiração, em outras regiões são encontradas outras espécies que possuem outro tipo de propriedades em seu veneno, como por exemplo as propriedades proteolíticas (necrosante) (FIOCRUZ, 2020).

Jibóia (Boa constrictor): Essa espécie vive em matas, cerrado, mais precisamente em locais fechados e que podem se camuflar facilmente com seu corpo manchado no meio das folhas secas e úmidas, podendo medir até 4 metros e viver por 20 anos. A Jibóia reproduz de 8 a 50 filhotes por ninhada e é bastante comum em veredas (FIOCRUZ, 2020).

\section{AVIFAUNA}

De acordo com o Livro Vermelho das Espécies Ameaçadas de Extinção, as aves são os vertebrados terrestres no qual chama atenção nas paisagens, sendo possível observar grande variedade da espécie em vários locais, no bioma do cerrado foram identificadas 837 espécies de aves, com apenas 32 espécies endêmicas $(3,4 \%)$, o que é considerado um número baixo (BRASIL, 2011).

Curicaca (Theristicus caudatus): A espécie exibe um bico longo e curvo, com asas largas de coloração clara, no voo apresenta manchas claras no lado superior da asa enquanto no inferior apresenta coloração escura, são encontradas geralmente em pares e formam bando para pernoitar (GWINNE et al., 2010).

Sabiá (Mimus sp): Conhecido pelo seu canto, no qual exibe notas agudas, desafinadas e meio metálicas com repetições, o sabiá apresenta o bico anel ocular e pernas amarelas, com o centro da barriga branco e o amarelo predominando suas asas (GWINNE et al. 2010).

Urubu de Cabeça Preta (Coragyps atratus): Sua ocorrência é comum, exibe sua cabeça e pescoços nus, cinza escuro, com plumagem negro-fosca, suas asas são largas e cauda curta, conhecido por se alimentar de restos de carniças porem pode capturar presas vivas (GWINNE et al. 2010).

Arara (Ara. ararauna): É razoavelmente comum, exibe um colorido intenso de azul, com penas amarelas por baixo, o qual a deixa inconfundível, gosta de se alimentar de frutos de palmeiras e dona de um grito característico. (GWINNE et al., 2010). 


\section{RECIMA21 - REVISTA CIENTÍFICA MULTIDISCIPLINAR ISSN 2675-6218}

CONSERVAÇÃO DA BIODIVERSIDADE: LEVANTAMENTO DA FAUNA EM UMA ÁREA DE CERRADO NO MUNICÍPIO DE JOÃO PINHEIRO-MG, COMO FERRAMENTA DE ENSINO PARA EDUCAÇÃO AMBIENTAL Cássia Crisélem Lobo Moura, Keroly Cristine Soares de Oliveira, Wanderson Alves Pereira, Saulo Gonçalves Pereira

Saracura-três-potes (Aramides. cajaneus): Considerada comum, a Saracura vive próxima de águas, dona de um bico esverdeado com a ponta amarela, com suas penas ajuda a ficar escondida sobre a vegetação, e apresenta um canto potente e familiar (GWINNE et al., 2010).

Periquito (Brotogeris tirica): Comum em áreas verdes, possui um bico claro e pelas verdes, com algumas manchas vermelhas e marrom, costuma a andar em bandos e são bem barulhentos.

Ema (Rhea. americana): Considerada a maior ave Brasileira, chama atenção pelo seu tamanho, com plumagem marrom acinzentada, e o peito branco, o macho se diferencia por essa parte ser preta, possuem pernas fortes e pés com três dedos (GWINNE et al., 2010).

Gralha (Cyanocorax chrysops): Possui assas grandes e cauda curta, e um topete na cabeça, com penas superiores preto azulado e inferior branca, ela vive em grupo e são conhecidas por fazerem muito barulho (GWINNE et al., 2010).

João de barro (Furnarius rufus): É uma espécie comum, principalmente em pastos e próximo a fazendas, sua cor marrom enferrujado toma conta de suas asas, porem por baixo e branco, conhecido por fazer ninhos excelentes e uma ave populosa no Brasil (GWINNE et al., 2010).

\section{MASTOFAUNA}

Os mamíferos são o segundo grupo mais diverso entre os vertebrados terrestres no bioma Cerrado, representando 15\% das espécies conhecidas, o qual ajuda ter maior número de pesquisas e trabalhos sobre ele. Para a avaliação de conservação da biodiversidade e fundamental encontrar indícios de mamíferos, pois, são considerados indicadores do estado de preservação ambiental (BRASIL, 2011).

Miquinho (Callithrix penicillata): São primatas diurnos de pequeno porte, não estão entre os animais em risco de extinção, mas sua ação antrópica sobre os animais e seu habitat (principalmente mata atlântica e cerrado) tem gerado a disseminação destes primatas e em algumas regiões estão sendo considerados invasores, colocando em risco outras espécies, por serem exóticos do cerrado, tendo sua vinda da Caatinga (BRASIL, 2011).

Guariba (Alouta. Guariba): O Bugio-ruivo, apresenta inúmeras diferenças fisiológicas, anatômicas e comportamentais de outros gêneros de primatas e pode se encontrar em risco de extinção em alguns Estados brasileiros. Exibem características como a cauda preênsil e vive nas árvores, e apresentam ampla distribuição em áreas tropicais e subtropicais (BRASIL, 2011).

Tatu galinha (Dasypus novemcinctus): Os biomas brasileiros de maior ocorrência dessa espécie são a Amazônia, Cerrado, Mata Atlântica, Pantanal, Campos Sulinos. Essa espécie possui a maior distribuição geográfica entre os tatus. Os tatus possuem variadas características morfológicas que estão diretamente ligadas a estratégias de alimentação. Como são animais escavadores, têm os membros curtos e espessos o que ajuda gerar uma grande força para escavar o solo e encontrar alimentos (BRASIL, 2011). 


\section{RECIMA21 - REVISTA CIENTÍFICA MULTIDISCIPLINAR ISSN 2675-6218}

CONSERVAÇÃO DA BIODIVERSIDADE: LEVANTAMENTO DA FAUNA EM UMA ÁREA DE CERRADO NO MUNICÍPIO DE JOÃO PINHEIRO-MG, COMO FERRAMENTA DE ENSINO PARA EDUCAÇÃO AMBIENTAL Cássia Crisélem Lobo Moura, Keroly Cristine Soares de Oliveira, Wanderson Alves Pereira, Saulo Gonçalves Pereira

Gambá de orelha branca (Didelphis albiventris): Com a destruição das florestas que é seu habitat sua sobrevivência é ameaçada, além de ser um dos poucos mamíferos que vive em áreas urbanas e principalmente rurais, ele corre risco pois é perseguido e morto de forma cruel, o que é bastante preocupante pois ele é um agente importante no controle biológico (IRBCB, 2012).

Jaguatirica (Lepardus sp.): É uma espécie de porte médio com $77,3 \mathrm{~cm}$ de comprimento, cauda proporcionalmente ao corpo, com média de $35,4 \mathrm{~cm}$ e peso em torno de $11 \mathrm{~kg}$, corpo esbelto, cabeça e patas grandes, um animal que sofreu muito com a caçada e a degradação do homem no meio ambiente (BRASIL, 2011).

Raposa (Lycalopex vetulus): A raposa-do-campo, é a única espécie de canídeo brasileiro endêmica do Cerrado, bioma sob alta pressão antrópica e com menos de $20 \%$ de sua área original ainda em estado primitivo, Endêmica do Brasil. A distribuição geográfica da raposa-do-campo originalmente parece estar associada aos limites de extensão do Cerrado, áreas de vegetação savânica. Com a pelagem escura e com o corpo e rosto pequeno e uma macha escura na cauda, que é sua característica (BRASIL, 2011).

Cão doméstico (Canis lúpus familiares): O Cão doméstico pode ter várias espécies, o que muda suas características, dependendo da mesma, é um animal mais dócil e controlado facilmente. Em algumas áreas, os cães são os carnívoros mais abundantes, representando uma grande ameaça para as espécies nativas e perturbando de forma significativa os ecossistemas (GALETTI; SAZIMA, 2006).

Anta (Tapirus terrestris): É um mamífero herbívoro que faz um papel muito importante nas florestas que é a dispersão de sementes, essa espécie apresenta hábitos solitários, normalmente é vista no período da noite (MEDICI. et al., 2010).

Ouriço-cacheiro (Erinaceus europaeus): É um mamífero onívoro, ele é fácil de ser identificado o ouriço-cacheiro possuem pelos modificados em espinhos que ajudam na sua defesa contra predadores, possui habito noturno (SANTOS, 2019).

Cachorro do mato (Cerdocyon thous): Habitam regiões de áreas abertas e cerrados, esses canídeos possuem uma dieta onívora que pode mudar dependendo do habitat que se encontram são territorialistas e caçadores solitários (MICHALSKI et al., 2006).

\section{CONTEXTUALIZAÇÃO DA FAUNA DENTRO DA BNCC E TEMAS TRANSVERSAIS}

De acordo com a BNCC, o tema Conservação de Fauna está inserido na unidade temática "vida e universo" com os objetivos "Diversidade de ecossistemas; Fenômenos naturais e impactos ambientais; Programas e indicadores de saúde pública" com a habilidade " (EF07Cl07). Caracterizar os principais ecossistemas brasileiros quanto à paisagem, à quantidade de água, ao tipo de solo, à disponibilidade de luz solar, à temperatura etc., correlacionando essas características à flora e fauna 


\section{RECIMA21 - REVISTA CIENTÍFICA MULTIDISCIPLINAR ISSN 2675-6218}

CONSERVAÇÃO DA BIODIVERSIDADE: LEVANTAMENTO DA FAUNA EM UMA ÁREA DE CERRADO NO MUNICÍPIO DE JOÃO PINHEIRO-MG, COMO FERRAMENTA DE ENSINO PARA EDUCAÇÃO AMBIENTAL

específicas". Dessa maneira, o tema "fauna" deve estar inserido no contexto educacional de forma efetiva (BRASIL, 2017, p. 355 e 358) De acordo com BNCC:

[...] "cabe aos sistemas e redes de ensino, assim como às escolas, em suas respectivas esferas de autonomia e competência, incorporar aos currículos e às propostas pedagógicas a abordagem de temas contemporâneos que afetam a vida humana em escala local, regional e global, preferencialmente de forma transversal e integradora. Entre esses temas, destacam-se: direitos da criança e do adolescente (Lei nํ 8.069/199016), educação para o trânsito (Lei no 9.503/199717), educação ambiental (Lei no 9.795/1999, Parecer CNE/CP no 14/2012 e Resolução CNE/CP no 2/201218), educação alimentar e nutricional (Lei no 11.947/200919), processo de envelhecimento, respeito e valorização do idoso (Lei no 10.741/200320), educação em direitos humanos (Decreto no 7.037/2009, Parecer CNE/CP no 8/2012 e Resolução CNE/CP no 1/201221), educação das relações étnico-raciais e ensino de história e cultura afro-brasileira, africana e indígena [...] (BRASIL, 2017, p. 45).

E ainda a educação visa "Construir argumentos com base em dados, evidências e informações confiáveis [...] que promovam a consciência socioambiental [...] (BRASIL, 2017, p. 44).

Observa-se que a Educação Ambiental deve ser tratada em forma de Tema Transversal, na Educação Infantil e Ensino Fundamental. Dessa maneira o trabalho sobre biodiversidade com dados locais é de grande importância para o aprendizado, pois as crianças conhecendo a fauna de sua região criam uma identidade fazendo com que ao respeito à fauna seja maior (BRASIL, 1997; BRASIL, 1999; BRASIL, 2017).

Contudo, a Educação Ambiental é citada enquanto determinadas habilidades ou aprendizagens essenciais, porém sem apresentar o termo Educação Ambiental propriamente dito.

A fauna brasileira é muito rica, principalmente entre os invertebrados. Esta riqueza reflete a adaptação aos diversos tipos vegetacionais encontrados no Brasil. O endemismo é outra característica marcante da fauna brasileira. Acredita-se que 39\% dos mamíferos da Mata Atlântica sejam endêmicos. Por sua vez, o Cerrado é uma das regiões de maior biodiversidade do mundo e estima-se que possua mais de 800 espécies de aves. É considerado um "hotspot" de conservação, por ser um dos biomas mais ricos e ameaçados do mundo (KLINK; MACHADO, 2005; BRASIL, 2010).

Estudos etnozoológicos propõem entender as relações entre as culturas humanas e os animais, incluindo a classificação e nomenclatura dos animais através do conhecimento popular (etnotaxonomia) e o uso de animais domésticos e selvagens. Tais estudos contribuem para acoplar os conhecimentos científicos aos saberes tradicionais de comunidades distintas sobre animais e meio ambiente (MARIN et al., 2003). E tais resultados colaboram com os processos de educação ambiental, tendo o papel de desenvolver a compreensão da natureza e analisar a inseparável relação entre os diferentes elementos que compõem o ambiente, especialmente a fauna (LIMA; POZZOBON, 2005; PEREIRA, 2017).

A Educação Ambiental é uma área da educação cujo objetivo é a disseminação do conhecimento sobre o meio ambiente, a fim de ajudar na sua preservação e utilização sustentável 


\section{RECIMA21 - REVISTA CIENTÍFICA MULTIDISCIPLINAR ISSN 2675-6218}

CONSERVAÇÃO DA BIODIVERSIDADE: LEVANTAMENTO DA FAUNA EM UMA ÁREA DE CERRADO NO MUNICÍPIO DE JOÃO PINHEIRO-MG, COMO FERRAMENTA DE ENSINO PARA EDUCAÇÃO AMBIENTAL Cássia Crisélem Lobo Moura, Keroly Cristine Soares de Oliveira, Wanderson Alves Pereira, Saulo Gonçalves Pereira

dos seus recursos, é uma maneira de mudar os hábitos da sociedade. "O papel da Educação Ambiental, nesse contexto, torna-se mais urgente. Precisamos oferecer mais formação. A educação ainda "treina" a (o) estudante para ignorar as consequências ecológicas dos seus atos". (DIAS, 2004, p. 16). É preciso, por parte de toda a sociedade, uma conscientização ecológica, pois os impactos ambientais são decorrentes da ação do homem, que é a principal causa de desequilíbrio ecológico na atualidade, como o desmatamento, caça e pesca sem controle, aliado a urbanização em área de matas e florestas.

\section{CONSIDERAÇÕES FINAIS}

Considerou-se que o objetivo maior do trabalho foi construir um levantamento qualitativo da fauna, apresentando a importância de processos educativos para a conservação ambiental. Pelos resultados obtidos, pode-se considerar que a metodologia empregada no estudo foi convergente.

A fauna da região apresentou riqueza de espécies consideráveis, mostrando uma comunidade com espécies comuns e outras de pouca frequência. Foi observado a frequência de mamíferos no local, o que possibilita considerar um padrão, mostrando a fidelidade dos mamíferos noturnos com seu habitat.

Com a identificação dos animais presentes na área do estudo, foi possível considerar que no local há uma diversidade de animais silvestres, mostrando também que esses são ameaçados consideravelmente pela ação humana, em todas as formas, dentre as quais observamos: desmatamento do seu habitat, plantio, queimadas que ligam a introdução do pasto na região.

Esses dados são de extrema importância para futuros trabalhos e chamando a atenção para estudos mais detalhados sobre a área, promovendo a eficácia e melhor monitoramento sobre esses animais. A cartilha nesse caso será de extrema importância. (Cartilha em Anexo).

\section{REFERÊNCIAS}

ADELITA, G. P. C. et al. Exposição "Conhecer para preservar: fauna e flora regional" contribuindo para a educação ambiental e formação cidadã consciente. 2o Congresso Internacional de Tecnologias para o Meio Ambiente. Bento Gonçalves - RS, Brasil, 28 a 30 de abril de 2010.

AGNELLO, S. Composição, estrutura e comunidade de aves da Mata Atlântica no Parque Estadual da Serra do Mar - Núcleo Cubatão, São Paulo. Dissertação (Mestrado) - Escola Superior de Agricultura "Luiz de Queiroz", Universidade de São Paulo, São Paulo, 2007.

ALMEIDA, D. Recuperação ambiental da Mata Atlântica. Ilhéus: Editus, 2000.

ALVES, E. F.; OLIVEIRA, I. S.; ALVES, C. N. Trilha ecológica pedagógica: um caminho para o ensino da educação ambiental em uma escola pública do município de Manaus (AM). Revista Brasileira de Educação Ambiental, v. 13, p. 153 169, 2018. DOI: 10.34024/revbea.

ANSELMO, J. S.; AIRES, I. C. S.; LIMA, R. A. A educação ambiental e o ensino de biologia em uma escola privada no município de Porto Velho-RO. Semana Educa, v. 1, p.1-9, 2013. 


\section{RECIMA21 - REVISTA CIENTÍFICA MULTIDISCIPLINAR ISSN 2675-6218}

CONSERVAÇÃO DA BIODIVERSIDADE: LEVANTAMENTO DA FAUNA EM UMA ÁREA DE CERRADO NO MUNICÍPIO DE JOÃO PINHEIRO-MG, COMO FERRAMENTA DE ENSINO PARA EDUCAÇÃO AMBIENTAL Cássia Crisélem Lobo Moura, Keroly Cristine Soares de Oliveira, Wanderson Alves Pereira, Saulo Gonçalves Pereira

BECKER, M.; DALPONTE, J. C. Rastros de mamíferos silvestres brasileiros: guia de campo. Brasília: IBAMA, 1999. 180 p.

BIZERRIL, M. Vivendo no Cerrado e aprendendo com ele. São Paulo: Saraiva, 2009. 79 p.

BRASIL. Parâmetros Curriculares Nacionais: introdução. Brasília, DF: MEC, 1997.

BRASIL. Lei no 9795 de 27 de abril de 1999 (Política Nacional de Educação Ambiental). Brasília, DF: Ministério da Educação, 1999.

BRASIL. Biodiversidade. Brasília, DF: Ministério do Meio Ambiente, 2010. Disponível em: http://www.icmbio.gov.br/cbc/conservacao-da-biodiversidade/biodiversidade.html. Acesso em 16/03/19. Acesso em: 01 out. 2020

BRASIL. Espécies da fauna brasileira ameaçadas de extinção. Brasília, DF: Ministério do Meio Ambiente, 2011. Disponível em: https://www.mma.gov.br/biodiversidade/conservacao-deespecies/fauna-ameacada/fauna.html. Acesso em: 16 maio 2020.

BRASIL. Base Nacional Comum Curricular. Brasília: MEC, 2017. Disponível em: http://basenacionalcomum.mec.gov.br/images/BNC C 20dez site.pdf. Acesso em: 22 ago. 2019.

CARLOS, J. B.; SILVA, da D. Desenvolvimento sustentável e educação ambiental: uma trajetória comum com muitos desafios. RAM, REV. ADM. MACKENZIE, São Paulo, v. 12, n. 3, p. 51-82, 2011

DIAS, G. F. Educação Ambiental: princípios e práticas. 9. ed. São Paulo: Gaia, 2004.

DURIGAN, G. et al. Manual para recuperação da vegetação de cerrado. 3. ed. São Paulo: Cetesb, 2011. 26 p.

EITEN, G. Delimitação do conceito de Cerrado. Arquivos do Jardim Botânico, Rio de janeiro, v. 21, p.125-134, 1977.

GALETTI, M.; SAZIMA, I. Impacto de cães ferais em um fragmento urbano de Floresta Atlântica no sudeste do Brasil. Natureza e Conservação, v. 01, p. 58-63, 2006.

GIL, A. C. Métodos e técnicas de pesquisa social. São Paulo: Atlas, 1999.

GWINNE, J. A.; RIDGELY, R. S; TUDOR, G.; ARGEL, M. Aves do Brasil: pantanal \& cerrado. São Paulo, SP: Editora Horizonte, 2010. vol.1.

ICMBIO. Ministério do Meio Ambiente. Avaliação do Estado de conservação da herpetofauna no Brasil. 2018.

IRBCB. INSTITUTO RÂ-BURGO PARA CONSERVAÇÃO DA BIODIVERSIDADE. Mamíferos. 2012. Disponível em: http://www.ra-bugio.org.br/ver especie.php?id=55. Acesso em: 22 ago. 2020.

IUCN. IUCN Red List of Threatened Species. Version 2019. Disponível em: www.iucnredlist.org. Acesso em: 03 jun. 2019.

JACOBI, P. Educação Ambiental cidadania e sustentabilidade. Cadernos de Pesquisa. n. 118, p. 189-205, mar. 2003

JUAREZ, K. M. Mamíferos de médio e grande porte nas unidades de conservação do Distrito Federal. 2008. 153 f. Tese (Doutorado em Biologia Animal) - Instituto de Ciências Biológicas da UnB, Universidade de Brasília, Distrito Federal, 2008. 


\section{RECIMA21 - REVISTA CIENTÍFICA MULTIDISCIPLINAR ISSN 2675-6218}

CONSERVAÇÃO DA BIODIVERSIDADE: LEVANTAMENTO DA FAUNA EM UMA ÁREA DE CERRADO NO MUNICÍPIO DE JOÃO PINHEIRO-MG, COMO FERRAMENTA DE ENSINO PARA EDUCAÇÃO AMBIENTAL Cássia Crisélem Lobo Moura, Keroly Cristine Soares de Oliveira, Wanderson Alves Pereira, Saulo Gonçalves Pereira

KLINK, C. A.; MACHADO, R. B. A conservação do cerrado brasileiro. Megadiversidade, Brasília, v. 1, n. 1, p. 145-147, jul. 2005.

LIMA, D.; POZZOBON, J. Amazônia socioambiental. Sustentabilidade ecológica e diversidade social. Estudos Avançados, v. 19, n. 54, p. 45-76, 2005.

LIMA, E. F.; FILHO, J. P. S.; ARAÚJO, A. F. S. Dicionário de termos técnicos tratados em Ecologia. Paranaíba, 2016.

MACHADO, A. B. M. et al., Livro vermelho da fauna brasileira ameaçada de extinção. Belo Horizonte: Fundação Biodiversitas, 2008.

MARIN, A. A.; OLIVEIRA, H. T.; COMAR, V. A educação ambiental num contexto de complexidade do campo teórico da percepção. Interciência, v. 28, n. 10, p. 616-619, 2003

MEDICI, E. P.; et al., Avaliação do risco de extinção da Anta brasileira. Avaliação do Estado de Conservação dos Ungulados. Biodiversidade Brasileira (2012) Ano II, № 1, 3-11. Instituto Chico Mendes de Conservação da Biodiversidade. Disponível em: https://www.icmbio.gov.br/portal/images/stories/biodiversidade/fauna-brasileira/avaliacao-dorisco/ungulados/tapirus terrestris anta brasileira.pdf. Acesso em: 01 nov. 2020.

NUNES, M. F. C.; Betini, G. S. Métodos de estimativa e abundância de psitacídeos. In: GALETTI, M. \& PIZO, M. A. Ecologia e conservação de psitacídeos no Brasil. Belo Horizonte: Melopsittacus Publicações Científicas, 2002.

OLIVEIRA, P. S.; MARQUIS, F. (eds.). The Cerrados of Brazil. Ecology and natural history of a neotropical savanna. New York: Columbia University Press, 2002.

PADUA, S. M; TABANEZ, M. F; SOUZA, M. das G. A abordagem participativa na educação para a conservação da natureza. In.: JR., L. C.; RUDRAN, R.; VALLADARES-PADUA, C. (Ed.). Métodos de estudos em biologia da conservação e manejo de fauna silvestre. Curitiba: Universidade Federal do Paraná, 2006. p. 543-555.

PARDINI, R. et al. Levantamento rápido de mamíferos terrestres de médio e grande porte. In.: CULLEN JÚNIOR, L.; RUDRAN, R.; VALLADARES-PADUA, C. (Orgs.). Métodos de estudos em biologia da conservação e manejo da vida silvestre. Curitiba: Universidade Federal do Paraná, 2003. p.181-201.

PEREIRA, M. E.; SILVEIRA, A. F.; SILVEIRA, S. O. Aspectos microscópicos do lábio do bugio ruivo (Alouatta fusca clamitans). Braz. J. Vet. Res. Anim. Sci., v. 39, n. 1, p. 9-12, fev. 2002.

PEREIRA, S. G. (org) Educação Ambiental: Faces e Possibilidades de uma Prática Possível. Republico Maldova: Novas Edições Acadêmicas, 2017. v. 1. 76p.

PEIXOTO, J. E; B.; JR, I. S; RODOVALHO, M. V.T. Levantamento da avifauna de áreas da usina vertente utilizado como objeto de avaliação ambiental. Ensaios Ciênc. v. 1; p. 15-109. 2007

RICKLEFS, R. E. A economia da natureza. Rio de Janeiro: Guanabara Koogan; 2011.

SAADI, A.; BEZERRA, F. H. R.; COSTA, F. D.; IGREJA, H. L. S.; FRANZINELLI, E. Neotectônica da plataforma Brasileira. In.: Quaternário do Brasil. Holos. São Paulo: Editora, 2005.

SANTOS, L. G. L. Neoplasia mamária espontânea em ouriço-terrestre (Ernaceus europaeus) RELATO DE CASO. UNICEPLAC. v. 1; p. 12-15; 2019. Disponível em: 


\section{RECIMA21 - REVISTA CIENTÍFICA MULTIDISCIPLINAR ISSN 2675-6218}

CONSERVAÇÃO DA BIODIVERSIDADE: LEVANTAMENTO DA FAUNA EM UMA ÁREA DE CERRADO NO MUNICÍPIO DE JOÃO PINHEIRO-MG, COMO FERRAMENTA DE ENSINO PARA EDUCAÇÃO AMBIENTAL Cássia Crisélem Lobo Moura, Keroly Cristine Soares de Oliveira, Wanderson Alves Pereira, Saulo Gonçalves Pereira

https://dspace.uniceplac.edu.br/bitstream/123456789/181/1/Lu\%C3\%ADsa Santos 001314.pdf Acesso em: 03 jul. 2020.

SAYRE, R.; ROCA, E.; SEDAGHATKISH, G.; YOUNG. B; KEEL. S.; SHEPPARD, S. Natureza em foco: A avaliação Ecológica Rápida. The NatureConservancy, p. 556, 2003.

SILVEIRA, L. F. et al. Para que servem os inventários de fauna?. Estud. av. v. 24, n. 68, p. 173-207, 2010.

SRBEK-ARAUJO, A. C.; CHIARELLO, A G. Is camera-trapping an efficient method for surveying mammals in Neotropical forests. A case study in south-eastern Brazil. Journal of Tropical Ecology 21, v. 1, n. 1, p. 121-125, 2005.

TAMAIO, I. A Mediação do professor na construção do conceito de natureza. Campinas, 2000. Dissertação (Mestrado.)- Unicamp, Campinas, 2000. Disponível em:

http://repositorio.unicamp.br/handle/REPOSIP/287068. Acesso em: 01 set. 2020.

TOBLER, M. W. et al. An evaluation of camera traps for inventorying large-and medium-sized terrestrial rainforest mammals. Animal Conservation, v. 11, p. 169- 178. 2008.

TOMAS, W. M.; MIRANDA, G. H. B. Uso de armadilhas fotográficas em levantamento populacionais. In.: CULLEN JR, L.; RUDRAN, R.; VALADARES, C. Métodos de estudo em Biologia da Conservação e Manejo da Vida Silvestre. Paraná: Editora UFPR, 2003. p. 243-265.

VOSS, R. S.; EMMONS. T. V. Mammalian diversity in neotropical lowland rainforests: a preliminary assessment. Bulletin of American Museum of Natural History. v. 1; p. 15-50. 1996. 


\section{RECIMA21 - REVISTA CIENTÍFICA MULTIDISCIPLINAR ISSN 2675-6218}

CONSERVAÇÃO DA BIODIVERSIDADE: LEVANTAMENTO DA FAUNA EM UMA ÁREA DE CERRADO NO MUNICÍPIO DE JOÃO PINHEIRO-MG, COMO FERRAMENTA DE ENSINO PARA EDUCAÇÃO AMBIENTAL Cássia Crisélem Lobo Moura, Keroly Cristine Soares de Oliveira, Wanderson Alves Pereira, Saulo Gonçalves Pereira

ANEXOS

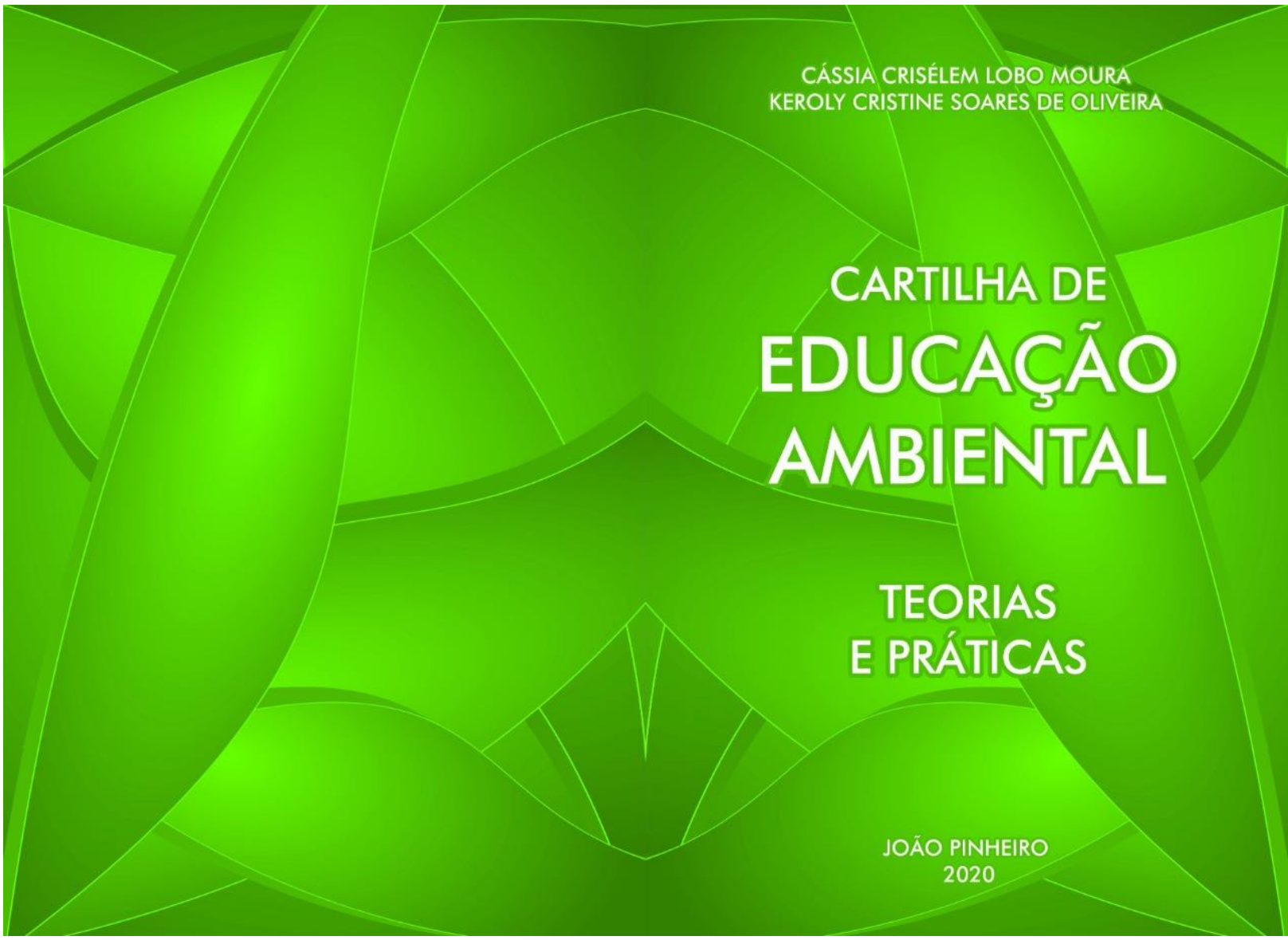




\section{RECIMA21 - REVISTA CIENTÍFICA MULTIDISCIPLINAR ISSN 2675-6218}

CONSERVAÇÃO DA BIODIVERSIDADE: LEVANTAMENTO DA FAUNA EM UMA ÁREA DE CERRADO NO MUNICÍPIO DE JOÃO PINHEIRO-MG, COMO FERRAMENTA DE ENSINO PARA EDUCAÇÃO AMBIENTAL

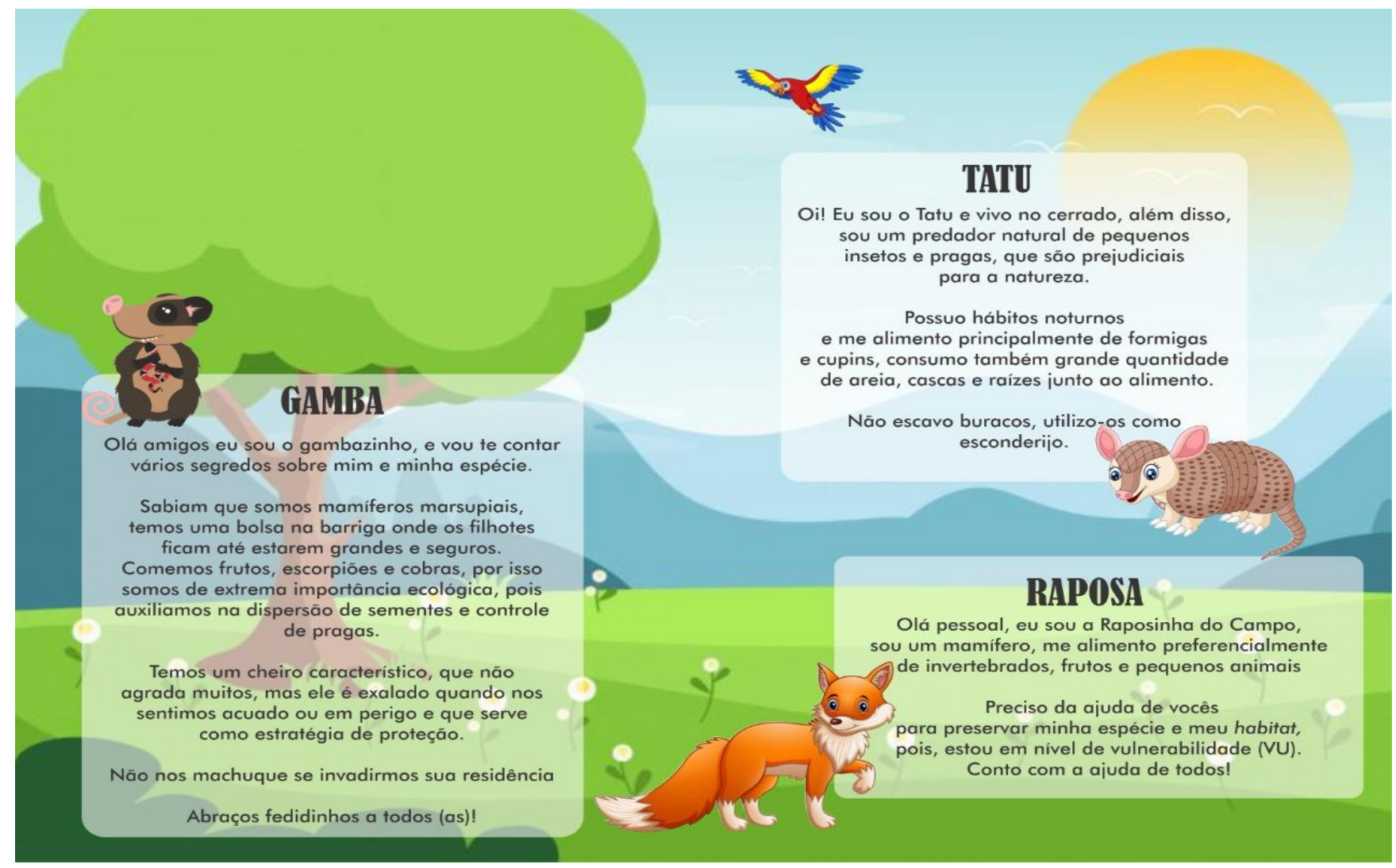

